\title{
Origens e ramificações do plexo braquial no cachorro-do-mato Cerdocyon thous (Linnaeus, 1766) ${ }^{1}$
}

\author{
Paulo Souza Junior ${ }^{2 *}$, Natan C. Carvalho², Karine Mattos ${ }^{2}$ e André L.Q. Santos ${ }^{3}$
}

\begin{abstract}
Souza Junior P., Carvalho N.C., Mattos K. \& Santos A.L.Q. 2014. [Origins and ramifications of brachial plexus in the crab-eating-fox Cerdocyon thous (Linnaeus, 1766).] Origens e ramificações do plexo braquial no cachorro-do-mato Cerdocyon thous (Linnaeus, 1766). Pesquisa Veterinária Brasileira 34(10):1011-1023. Laboratório de Anatomia Animal, Universidade Federal do Pampa, Rodovia BR 472, Km 592, Cx. Postal 118, Uruguaiana, RS 97500-970, Brazil. E-mail: paulosouza@unipampa.edu.br

This study aimed to describe the origin and branching of nerves from twenty brachial plexuses of crab-eating foxes (Cerdocyon thous). Ten animals of the species, obtained post mortem from being run over on highways, were used for the study, in accordance with the authorization from IBAMA / SISBIO No. 33667-1. Once collected, the cadavers were fixed in $50 \%$ formaldehyde and kept for at least 14 days in a solution of $10 \%$ formaldehyde before dissections. After removal of skin, incisions in breast muscles and reflection of thoracic limbs allowed access to axillary space and the nerves could have trajects dissected individually to each muscle insertion. To improve visualization of the cervical and thoracic ventral roots that originated every single nerve, muscles that covered the intervertebral foramina, transverse processes and vertebral bodies were removed ventrally and the spinal cord exposed. Schematic drawings and photographic records documented the origin and branching of nerves. The twenty plexuses were resulted from connections between the ventral branches of the last three cervical spinal nerves (C6, C7 and C8) and first thoracic (T1). These branches derived the nerves suprascapular, subscapular, axillary, musculocutaneous, radial, median and ulnar to the intrinsic muscles and brachiocephalic, thoracodorsal, lateral thoracic, long thoracic, cranial and caudal pectoral nerves to the extrinsic muscles of the thoracic limb. It was found that the ventral rami of $\mathrm{C} 7$ were the main contributors in the formation of nerves $(61.5 \%)$, followed by C8 (55.4\%), T1 (41.2\%) and C6 (30.8\%). The t-test comparison between means at a significance level of $5 \%$ showed no differences in the origin of plexus when compared antimeres and sexes. Of the total of 260 dissected nerves, $68.8 \%$ originated by the combination of two or three roots, while only $31.2 \%$ were formed by a single root. The combination between C8 and T1 was the most frequent origin of nerves to the plexus (23.8\%) in this species. Comparing the origin, branching and innervation area of the brachial plexus in $C$. thous with other domestic and wild species, there was a greater similarity with the domestic dog. These results may give the anatomical basis to diagnosis of neuromuscular disorders, anesthetic blocks techniques and comparative morphofunctional analyzes involving this species.
\end{abstract}

INDEX TERMS: Brachial plexus, morphology, wild carnivores, animal anatomy, Cerdocyon thous.

\footnotetext{
${ }^{1}$ Recebido em 12 de março de 2014.

Aceito para publicação em 27 de julho de 2014.

${ }^{2}$ Laboratório de Anatomia Animal, Universidade Federal do Pampa (Unipampa), Campus Uruguaiana, Rodovia BR-472 Km 592, Caixa Postal 118, Uruguaiana, RS 97500-970, Brasil. *Autor para correspondência: paulosouza@unipampa.edu.br

${ }^{3}$ Laboratório de Pesquisa em Animais Silvestres (Lapas), Faculdade de Medicina Veterinária, Universidade Federal de Uberlândia (UFU), Av. Amazonas 2245, Jardim Umuarama, Uberlândia, MG 38405-302, Brasil.
}

RESUMO.- Este estudo teve o objetivo de descrever a origem e ramificação dos nervos de vinte plexos braquiais de cachorro-do-mato (Cerdocyon thous). Dez animais da espécie, obtidos post mortem por atropelamento em rodovias, foram utilizados para o estudo, de acordo com a autorização do IBAMA/SISBIO no3667-1. Depois de coletados, os cadáveres foram fixados em solução de formaldeído a $50 \%$ e conservados por pelo menos 14 dias em solução de for- 
maldeído a $10 \%$ antes das dissecções. Após remoção da pele, incisões na musculatura peitoral e afastamento dos membros, acessou-se o espaço axilar e os nervos do plexo tiveram seu trajeto dissecados individualmente até sua inserção muscular. Para melhorar a visualização dos ramos ventrais cervicais e torácicos que originavam cada nervo, removeram-se a musculatura que encobria os forames intervertebrais, os processos transversos e os corpos vertebrais ventralmente, expondo inclusive a medula espinhal. Registros fotográficos e desenhos esquemáticos documentaram a origem e ramificação dos nervos. Os vinte plexos braquiais foram resultantes das conexões entre os ramos ventrais dos três últimos nervos espinhais cervicais (C6, C7 e C8) e do primeiro torácico (T1). Estes ramos derivaram os nervos supra-escapular, subescapular, axilar, musculocutâneo, radial, mediano, ulnar para a musculatura intrínseca e os nervos braquiocefálico, toracodorsal, torácico lateral, torácico longo, peitoral cranial e peitoral caudal para a musculatura extrínseca do membro torácico. Constatou-se que os ramos ventrais de $\mathrm{C} 7$ foram os que mais contribuíram na formação de nervos $(61,5 \%)$, seguido de C8 (55,4\%), de T1 (41,2\%) e de C6 (30,8\%). 0 teste $t$ de comparação entre as médias, ao nível de significância de $5 \%$, não demonstrou diferenças na origem do plexo quando comparados os antímeros e os sexos. Do total dos 260 nervos dissecados, $68,8 \%$ foram originados pela combinação de dois ou três ramos, enquanto apenas $31,2 \%$ tiveram formação por um único ramo. A combinação entre C8 e T1 foi a que mais formou nervos para o plexo $(23,8 \%)$ nesta espécie. Quando comparadas a origem, ramificação e área de inervação do plexo braquial do $C$. thous com outras espécies domésticas e silvestres, verificou-se maior semelhança com o cão doméstico. Os resultados deste estudo podem embasar o diagnóstico de disfunções neuromusculares, as técnicas de bloqueios anestésicos e análises morfofuncionais comparativas envolvendo esta espécie.

TERMOS DE INDEXAÇÃO: Plexo braquial, morfologia, carnívoros silvestres, Cerdocyon thous.

\section{INTRODUÇÃO}

Cerdocyon thous Linnaeus, 1766, conhecido por cachorro-do-mato ou graxaim-do-mato, é um canídeo silvestre de ocorrência em todo território brasileiro (a exceção do Acre e Amazonas), bem como na Colômbia, Venezuela, Uruguai, Paraguai e nordeste Argentino (Berta 1982, Machado \& Hingst-Zaher 2009). Segundo Tchaicka et al. (2007), há cinco subespécies com distribuições geográficas distintas. Os adultos possuem massa corporal entre quatro e $11 \mathrm{~kg}$, a cabeça e tronco medem entre 60 e $70 \mathrm{~cm}$ e a cauda cerca de $30 \mathrm{~cm}$ (Berta 1982). Com hábitos noturnos e crepusculares, é um onívoro, generalista e oportunista com aparelho mastigatório para dieta à base de pequenos vertebrados, frutos e invertebrados (Langguth 1975, Berta 1982). A espécie é comumente exibida em zoológicos de todo o mundo e, apesar de não parecer ameaçada de extinção, muitas populações sofrem os impactos da caça, por serem considerados equivocadamente ameaçadores à pecuária, e de atropelamentos nas rodovias brasileiras (Cheida et al. 2011).
A espécie é citada frequentemente em estudos de osteometria comparada em contextos filogenéticos e evolutivos conforme publicado por Christiansen (1999), Lyras \& Van Der Geer (2003), Ferguson \& Lariviére (2004), Takemura et al. (2004) e Goswami (2006). Entretanto, há poucos trabalhos descritivos sobre a morfologia funcional do C. thous. Foram encontradas descrições anatômicas da distribuição dos nervos glúteos (Benedicto et al. 2008), da ramificação da artéria femoral (Benedicto \& Senos 2008), morfometria testicular e dos túbulos seminíferos (Caldeira et al. 2010), do sistema digestório (Nascimento et al. 2010, Heleno et al. 2011), da vascularização renal (Menezes et al. 2011), da topografia do cone medular (Pinheiro 2011), da musculatura do antebraço (Vaz et al. 2011), da anatomia radiográfica do esqueleto (Barisson et al. 2012), preliminares da formação do plexo lombossacral (Lorenzão et al. 2012, Lugoch et al. 2012) e do plexo braquial (Carvalho et al. 2012, Zimpel et al. 2012), da laringe (Mattos et al. 2012) e morfometria do forame mandibular (Souza Junior et al. 2013).

0 plexo braquial é um grande plexo somático formado por um padrão variado de uniões entre os ramos ventrais do sexto, sétimo e oitavo nervos espinhais cervicais (C6, C7 e C8) e pelo primeiro e segundo nervos espinhais torácicos (T1 e T2) (Ghoshal 1986b, König et al. 2011). Os nervos do plexo atravessam a musculatura intertransversa, cruzam a borda ventral do m. escaleno e se estendem até o membro através do espaço axilar (Evans \& De Lahunta 2013). Suas fibras nervosas percorrem curtas distâncias e segregam-se em combinações variáveis para formar os nervos que suprem os músculos e a pele do membro torácico (Evans \& De Lahunta 2013). No cão doméstico, mais da metade dos plexos braquiais são formados sem a participação de C5 ou T2 e, quando ocorre, a contribuição é diminuta (Allam et al. 1952). Os nervos que são ramos do plexo braquial ou continuações do ramo ventral que o originou são: braquiocefálico, supra-escapular, subescapular, axilar, musculocutâneo, radial, mediano, ulnar, tóracodorsal, torácico lateral, torácico longo, peitoral cranial e peitoral caudal (Evans \& De Lahunta 2013).

A morfologia fornece conhecimento que permite entender o modo como os animais interagem com o ambiente natural ou em cativeiro, podendo ser utilizada a favor da preservação das espécies (Moura et al. 2007). Em especial, o estudo comparativo da formação do plexo braquial entre espécies (Quadro 1) desperta interesse desde o século XIX (Paterson 1887) e, segundo Johnson et al. (2010), o seu entendimento permanece como uma das áreas mais desafiadoras da anatomia contemporânea. De forma aplicada, o estudo morfofuncional deste plexo facilita o diagnóstico de disfunções neuromusculares (Freeman et al. 2009) e norteia técnicas de bloqueio anestésico regionais (Futema et al. 1999, Johnson et al. 2010). Variações nos níveis de origens do plexo braquial podem estar relacionadas com fatores genéticos e embrionários, representados pela posição na qual os brotos dos membros se desenvolvem em relação ao neuro-eixo. De acordo com Carpenter (1978), quanto mais cefálica for esta relação, mais craniais serão os ramos que participam da formação do plexo. Trabalhos envolvendo a anatomia comparada do plexo braquial poderão ainda cor- 
Quadro 1. Ramos ventrais que participam da formação do plexo braquial em diferentes espécies de mamíferos

\begin{tabular}{|c|c|c|c|c|c|c|c|c|c|c|}
\hline \multirow[t]{2}{*}{ Nome vulgar } & \multirow[t]{2}{*}{ Nome científico } & \multicolumn{7}{|c|}{ Origem } & \multirow[t]{2}{*}{$\mathrm{n}$} & \multirow[t]{2}{*}{ Referência } \\
\hline & & $\mathrm{C} 4$ & $\mathrm{C} 5$ & $\mathrm{C} 6$ & $\mathrm{C} 7$ & $\mathrm{C} 8$ & T1 & $\mathrm{T} 2$ & & \\
\hline Coellho & Oryctolagus cuniculus & & $\mathrm{x}$ & $\mathrm{x}$ & $\mathrm{x}$ & $\mathrm{x}$ & $\mathrm{x}$ & & 1 & Paterson, 1887 \\
\hline Coala & Phascolarctos cinereus & & $\mathrm{x}$ & $\mathrm{x}$ & $\mathrm{x}$ & $\mathrm{x}$ & $\mathrm{x}$ & & 1 & Paterson, 1887 \\
\hline Rato & Rattus rattus & & $\mathrm{x}$ & $\mathrm{x}$ & $\mathrm{x}$ & $\mathrm{x}$ & $\mathrm{x}$ & & 1 & Paterson, 1887 \\
\hline Camelo & Camelus sp. & & & $\mathrm{x}$ & $\mathrm{x}$ & $\mathrm{x}$ & $\mathrm{x}$ & & 1 & Paterson, 1887 \\
\hline Langur-cinzento & Presbytis hosei & $\mathrm{x}$ & $\mathrm{x}$ & $\mathrm{x}$ & $\mathrm{x}$ & $\mathrm{x}$ & $\mathrm{x}$ & & 1 & Paterson, 1887 \\
\hline Gnu & Connochaetes sp. & & & $\mathrm{x}$ & $\mathrm{x}$ & $\mathrm{x}$ & $\mathrm{x}$ & & 1 & Paterson, 1887 \\
\hline Macaco-prego-de-cara-branca & Cebus capucinus & & $\mathrm{x}$ & $\mathrm{x}$ & $\mathrm{x}$ & $\mathrm{x}$ & $\mathrm{x}$ & & 1 & Paterson, 1887 \\
\hline Porquinho-da-índia & Cavia porcellus & & $\mathrm{x}$ & $\mathrm{x}$ & $\mathrm{x}$ & $\mathrm{x}$ & $\mathrm{x}$ & & 1 & Paterson, 1887 \\
\hline Porco-espinho & Coendou prehensilis & & & $\mathrm{x}$ & $\mathrm{x}$ & $\mathrm{x}$ & $\mathrm{x}$ & & 1 & Paterson, 1887 \\
\hline Canino & Canis lupus familiaris & & $\mathrm{x}$ & $\mathrm{x}$ & $\mathrm{x}$ & $\mathrm{x}$ & $\mathrm{x}$ & & 29 & Allam et al. 1952 \\
\hline Urso polar & Ursus maritimus & & & $\mathrm{x}$ & $\mathrm{x}$ & $\mathrm{x}$ & $\mathrm{x}$ & $\mathrm{x}$ & $?$ & $\begin{array}{l}\text { Matsushima 1966, Apud } \\
\text { Yoshitomi et al. } 2012\end{array}$ \\
\hline Elefante indiano & Elephas maximus & & & $\mathrm{x}$ & $\mathrm{x}$ & $\mathrm{x}$ & $\mathrm{x}$ & $\mathrm{x}$ & 1 & $\begin{array}{c}\text { Wakuri \& Kano 1966, Apud } \\
\text { Yoshitomi et al. } 2012\end{array}$ \\
\hline Equino & Equus caballus & & & $\mathrm{x}$ & $\mathrm{x}$ & $\mathrm{x}$ & $\mathrm{x}$ & $\mathrm{x}$ & 10 & Magilton et al. 1968 \\
\hline Bovino & Bos taurus & & & $\mathrm{x}$ & $\mathrm{x}$ & $\mathrm{x}$ & $\mathrm{x}$ & $\mathrm{x}$ & 10 & Magilton et al. 1968 \\
\hline Caprino & Capra hircus & & & $\mathrm{x}$ & $\mathrm{x}$ & $\mathrm{x}$ & $\mathrm{x}$ & & 10 & Magilton et al. 1968 \\
\hline Ovino & Ovis aries & & & $\mathrm{x}$ & $\mathrm{x}$ & $\mathrm{x}$ & $\mathrm{x}$ & & 10 & Magilton et al. 1968 \\
\hline Suíno & Sus scrofa & & $\mathrm{x}$ & $\mathrm{x}$ & $\mathrm{x}$ & $\mathrm{x}$ & $\mathrm{x}$ & & 10 & Magilton et al. 1968 \\
\hline Girafa & Giraffa camelopardalis & & & $\mathrm{x}$ & $\mathrm{x}$ & $\mathrm{x}$ & $\mathrm{x}$ & $\mathrm{x}$ & 1 & $\begin{array}{l}\text { Wakuri et al. 1970, Apud } \\
\text { Yoshitomi et al. } 2012\end{array}$ \\
\hline Porquinho-da-índia & Cavia porcellus & & $\mathrm{x}$ & $\mathrm{x}$ & $\mathrm{x}$ & $\mathrm{x}$ & $\mathrm{x}$ & $\mathrm{x}$ & $?$ & Cooper \& Schiller 1975 \\
\hline Goral japonês & Capricornis crispus & & & $\mathrm{x}$ & $\mathrm{x}$ & $\mathrm{x}$ & $\mathrm{x}$ & & 26 & Atoji et al. 1987 \\
\hline Ornitorrinco & Ornithorhynchus anatinus & $\mathrm{x}$ & $\mathrm{x}$ & $\mathrm{x}$ & $\mathrm{x}$ & $\mathrm{x}$ & $\mathrm{x}$ & & 3 & Koizumi \& Sakai 1997 \\
\hline Equidina & Tachyglossus aculeatus & $\mathrm{x}$ & $\mathrm{x}$ & $\mathrm{x}$ & $\mathrm{x}$ & $\mathrm{x}$ & $\mathrm{x}$ & & 2 & Koizumi \& Sakai 1997 \\
\hline Bicho-preguiça & Bradypus variegatus & $\mathrm{x}$ & $\mathrm{x}$ & $\mathrm{x}$ & $\mathrm{x}$ & $\mathrm{x}$ & $\mathrm{x}$ & & 4 & Amorim Junior et al. 2003 \\
\hline Capivara & Hydrochaeris hydrochaeris & $\mathrm{x}$ & $\mathrm{x}$ & $\mathrm{x}$ & $\mathrm{x}$ & $\mathrm{x}$ & $\mathrm{x}$ & & 5 & Fioretto et al. 2003 \\
\hline Mocó & Kerodon rupestris & & $\mathrm{x}$ & $\mathrm{x}$ & $\mathrm{x}$ & $\mathrm{x}$ & $\mathrm{x}$ & & 10 & Santana et al. 2003 \\
\hline Porco-espinho de crista & Hystrix cristata & & $\mathrm{x}$ & $\mathrm{x}$ & $\mathrm{x}$ & $\mathrm{x}$ & $\mathrm{x}$ & $\mathrm{x}$ & 4 & Aydin 2003 \\
\hline Felino doméstico & Felis catus & & & $\mathrm{x}$ & $\mathrm{x}$ & $\mathrm{x}$ & $\mathrm{x}$ & & 20 & Aubert et al. 2004; \\
\hline Macaco-prego & Cebus apella & $\mathrm{x}$ & $\mathrm{x}$ & $\mathrm{x}$ & $\mathrm{x}$ & $\mathrm{x}$ & $\mathrm{x}$ & $\mathrm{x}$ & 20 & Ribeiro et al. 2005 \\
\hline Catetos & Kerodon rupestri & $\mathrm{x}$ & $\mathrm{x}$ & $\mathrm{x}$ & $\mathrm{x}$ & $\mathrm{x}$ & $\mathrm{x}$ & $\mathrm{x}$ & 30 & Moura et al. 2007 \\
\hline Veado catingueiro & Mazama gouazoubira & & & $\mathrm{x}$ & $\mathrm{x}$ & $\mathrm{x}$ & $\mathrm{x}$ & & 14 & Melo et al. 2007 \\
\hline Babuíno Chacma & Papio ursinus & & $\mathrm{x}$ & $\mathrm{x}$ & $\mathrm{x}$ & $\mathrm{x}$ & $\mathrm{x}$ & $\mathrm{x}$ & 10 & Booth et al. 2007 \\
\hline Chinchila & Chinchilla lanigera & & & $\mathrm{x}$ & $\mathrm{x}$ & $\mathrm{x}$ & $\mathrm{x}$ & & 10 & Gamba et al. 2007 \\
\hline Paca & Agouti paca & & $\mathrm{x}$ & $\mathrm{x}$ & $\mathrm{x}$ & $\mathrm{x}$ & $\mathrm{x}$ & $\mathrm{x}$ & 8 & Scavone et al. 2008 \\
\hline Macaco-barrigudo & Lagothrix lagothricha & & $\mathrm{x}$ & $\mathrm{x}$ & $\mathrm{x}$ & $\mathrm{x}$ & $\mathrm{x}$ & & 1 & Cruz \& Adami 2010 \\
\hline Lobo-marinho & Arctocephalus australis & & & $\mathrm{x}$ & $\mathrm{x}$ & $\mathrm{x}$ & $\mathrm{x}$ & & 2 & Souza et al. 2010 \\
\hline Bonobo & Pan paniscus & & $\mathrm{x}$ & $\mathrm{x}$ & $\mathrm{x}$ & $\mathrm{x}$ & $\mathrm{x}$ & & 1 & Kikuchi et al. 2011 \\
\hline Esquilo-vermelho & Sciurus vulgaris & & $\mathrm{x}$ & $\mathrm{x}$ & $\mathrm{x}$ & $\mathrm{x}$ & & & 10 & Aydin 2011 \\
\hline Hipopótamo & Hippopotamus amphibius & & $\mathrm{x}$ & $\mathrm{x}$ & $\mathrm{x}$ & $\mathrm{x}$ & $\mathrm{x}$ & & 1 & Yoshitomi et al. 2012 \\
\hline Tamanduá-mirim & Tamandua tetradactyla & & $\mathrm{x}$ & $\mathrm{x}$ & $\mathrm{x}$ & $\mathrm{x}$ & $\mathrm{x}$ & & 4 & Cruvinel et al. 2012 \\
\hline Tamanduá-mirim & Tamandua tetradactyla & & $\mathrm{x}$ & $\mathrm{x}$ & $\mathrm{x}$ & $\mathrm{x}$ & $\mathrm{x}$ & & 2 & Cruz et al. 2012 \\
\hline Rato-toupeira-menor & Spalax leucodon & & $\mathrm{x}$ & $\mathrm{x}$ & $\mathrm{x}$ & $\mathrm{x}$ & $\mathrm{x}$ & & 10 & Aydin \& Karan 2012 \\
\hline Ratão-do-banhado & Myocastor coypus & & & $\mathrm{x}$ & $\mathrm{x}$ & $\mathrm{x}$ & $\mathrm{x}$ & & 10 & Guimarães et al. 2013 \\
\hline Veado catingueiro & Mazama gouazoubira & & & $\mathrm{x}$ & $\mathrm{x}$ & $\mathrm{x}$ & $\mathrm{x}$ & & 3 & Vieira et al. 2013 \\
\hline Veado catingueiro & Mazama gouazoubira & & & $\mathrm{x}$ & $\mathrm{x}$ & $\mathrm{x}$ & $\mathrm{x}$ & & 2 & Prestes et al. 2013 \\
\hline Cachorro-do-mato-de-orelha-pequena & Atelocynus microtis & & & $\mathrm{x}$ & $\mathrm{x}$ & $\mathrm{x}$ & $\mathrm{x}$ & & 1 & Pinheiro et al. 2013 \\
\hline
\end{tabular}

${ }^{a}$ Recebe também a contribuição da ramo ventral de C9 pois possui 8 vértebras cervicais.

roborar com a hipótese de que no processo evolutivo ocorreu uma migração cranial dos ramos dos nervos espinhais que participam da formação deste plexo (Parada et al. 1989).

Diante dessa relevância, objetivou-se descrever a origem e as ramificações do plexo braquial em $C$. thous e, assim, fornecer o embasamento anatômico necessário para as aplicações supracitadas.

\section{MATERIAL E MÉTODOS}

Foram analisados vinte membros torácicos e seus respectivos plexos braquiais em dez espécimes de Cerdocyon thous (oito fêmeas e dois machos) recolhidos mortos em rodovias da mesorregião sudoeste do Rio Grande do Sul (autorização do IBAMA/SISBIO nº33667-1) entre maio de 2012 e março de 2013. Os animais ti- nham idade superior a seis meses, pois apresentavam dentição permanente completa. Os cadáveres foram então transportados até o Laboratório de Anatomia Animal da Universidade Federal do Pampa (Unipampa), campus Uruguaiana-RS, onde foram fixados com injeções subcutâneas, intramusculares e intracavitárias de solução aquosa de formaldeído a $50 \%$ e posteriormente conservados imersos em cubas opacas de polietileno contendo solução aquosa de formaldeído a $10 \%$ por pelo menos catorze dias antes da dissecção.

Dissecções macroscópicas dos vinte membros torácicos foram realizadas para evidenciar os músculos bem como as origens e ramificações dos nervos formadores dos plexos braquiais. Após remoção completa da pele e fáscias, realizou-se uma incisão mediana na musculatura peitoral, se estendendo do manúbrio ao xifoide, seguida de abdução dos membros torácicos, o que permitiu 
a ampliação do espaço axilar para facilitar a dissecção individualizada dos nervos. Para melhorar a visualização dos ramos ventrais cervicais e torácico removeu-se a musculatura que encobria os forames intervertebrais com auxílio de pinça e rugina Farabeuf (10 $\mathrm{mm}$ ). Os processos transversos foram removidos com um alicate e a medula espinhal exposta ventralmente por abertura dos corpos vertebrais com uma broca vulcanite do tipo pera acoplada a uma parafusadeira elétrica (Black \& Decker ${ }^{\circledR}, 9,6 \mathrm{~V}$ ). Os nervos foram denominados em conformidade com o International Committee on Veterinary Gross Anatomical Nomenclature (2012), a exceção do nervo braquiocefálico que foi designado de acordo com Evans e De Lahunta (2013). Foram realizados registros fotográficos com câmera digital (Câmera Fujifilm ${ }^{\circledR}$ AV100, 12.0 Mpx) e desenhos esquemáticos de todos os plexos. Os dados contendo as origens de cada nervo foram tabulados em planilhas e os testes t de comparação de entre médias de antímeros e sexo ao nível de significância de $5 \%$ foram realizados no software BioEstat $5.3{ }^{\circledR}$.

\section{RESULTADOS}

As macrodissecções permitiram sistematizar e documentar os componentes do plexo braquial dos dez espécimes de Cerdocyon thous.

\section{Quanto à origem do plexo braquial}

Os vinte plexos braquiais foram resultantes das conexões entre os ramos ventrais dos três últimos nervos espinhais cervicais (C6, C7 e C8) e do primeiro torácico (T1). Estes ramos derivaram os nervos supra-escapular, subescapular, axilar, musculocutâneo, radial, mediano, ulnar para a musculatura intrínseca e os nervos braquiocefálico, tóracodorsal, torácico lateral, torácico longo, peitoral cranial e peitoral caudal para a musculatura extrínseca (Fig.1, 3 e 4). Os nervos frênicos direito e esquerdo, ainda que não participem do plexo braquial, foram originados a partir de C5 e C6 nos dez indivíduos.

Quando considerado o conjunto dos treze nervos dissecados nos 20 plexos $(n=260)$, constatou-se que os ramos ventrais de $\mathrm{C} 7$ foram os que mais contribuíram na formação de nervos $(61,5 \%)$, seguido por C8 $(55,4 \%)$, por T1 $(41,2 \%)$ e finalmente por C6 $(30,8 \%)$.

O somatório do número de contribuições de ramos ventrais para a formação dos vinte plexos foi semelhante entre os antímeros: 245 no esquerdo e 246 no direito. Ao todo, 491 ramos ventrais formaram 260 nervos e cada nervo foi formado, em média, pela combinação de praticamente dois ramos (1,88 ramos/nervo). Quando comparados os números de contribuições de cada ramo ventral entre antímeros, notou-se que C6 e C7 participaram mais nos antímeros esquerdos e C8 e T1 contribuíram mais nos antímeros direitos, ainda que estas diferenças não fossem significativas (p-valor =0,4911; $\alpha=0,05$ ) (Fig.2). Quando considerados os sexos, cada nervo foi formado em média por 1,94 ramos nas fêmeas e 1,67 nos machos, mesmo que esta diferença também não tenha sido significativa ( $\mathrm{p}$-valor $=0,1339$; $\alpha$ $=0,05$ ).

Uma simetria exata entre antímeros na origem dos nervos ocorreu em dois indivíduos (20\%). Ainda assim, as diferenças encontradas na distribuição dos nervos entre os plexos direito e esquerdo de um mesmo animal foram restritas, na maioria dos casos, a uma ou duas contribuições.

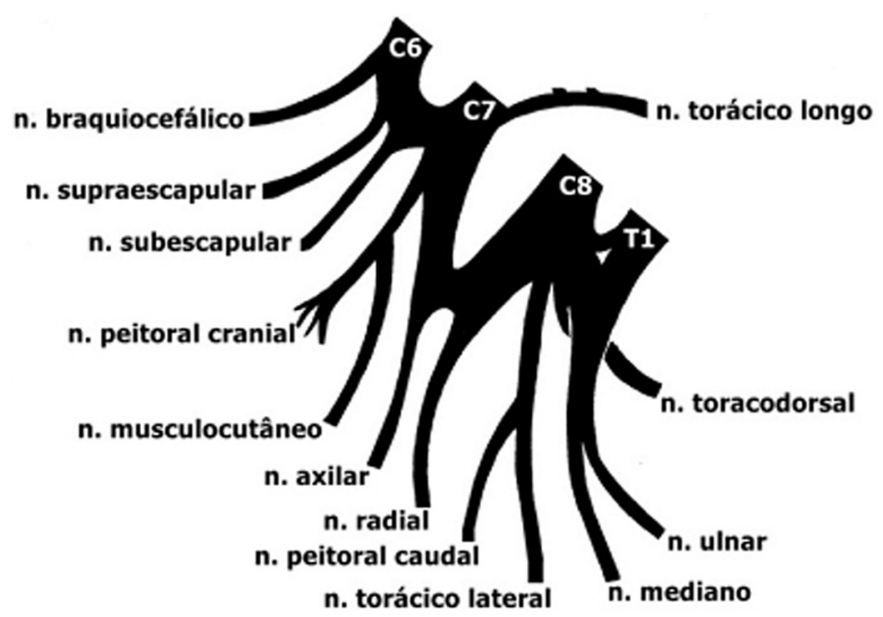

Fig.1. Representação esquemática da origem e distribuição mais comum dos nervos do plexo braquial em Cerdocyon thous.

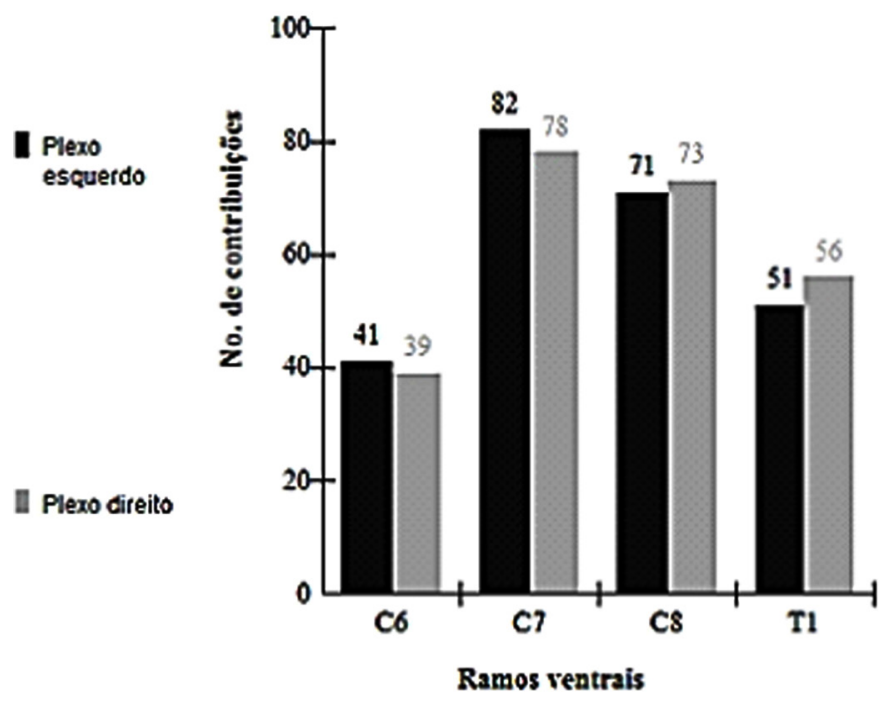

Fig.2. Comparação do número de contribuições dos ramos espinhais ventrais entre antímeros do plexo braquial de Cerdocyon thous $(n=20)$.

Quanto à distribuição dos nervos do plexo braquial (Quadros 2 e 3)

Nervo supra-escapular: foi derivado dos ramos ventrais de $\mathrm{C} 6$ e $\mathrm{C} 7$ em 75\% dos plexos e apenas por $\mathrm{C} 6$ nos demais 25\%. Esta origem restrita a C6 ocorreu em ambos antímeros de duas fêmeas e no plexo esquerdo de outra. No seu trajeto penetrou medialmente na região distal do espaço intermuscular entre os músculos subescapular e supra-espinhoso, suprindo o último, contornou cranialmente o colo da escápula, atravessou para a face lateral do membro distalmente ao acrômio e terminou oferecendo um ramo ao m. infraespinhoso e outro delgado à articulação escápulo-umeral.

Nervo subescapular: em $45 \%$ dos plexos originou-se de $\mathrm{C} 6$ e C7, em $40 \%$ de C7, em $10 \%$ de $\mathrm{C} 6$ e em $5 \%$ de $\mathrm{C} 7$ e C8. Apresentou-se como nervo único com trajeto até a face medial do m. subescapular, onde se dividiu em dois ramos, um cranial e outro caudal, para suprí-lo.

Nervo axilar: em $40 \%$ dos plexos formou-se a partir de C7 e C8, em $25 \%$ de C7, em $20 \%$ de $\mathrm{C} 6$ e C7 e em $15 \%$ de C6, C7 e C8. Este nervo transita entre a borda caudoventral 
do $\mathrm{m}$. subescapular e o $\mathrm{m}$. redondo maior inervando-os e então atravessa para a face lateral do membro onde supre o m. redondo menor e as porções escapular e acromial do m. deltoide.

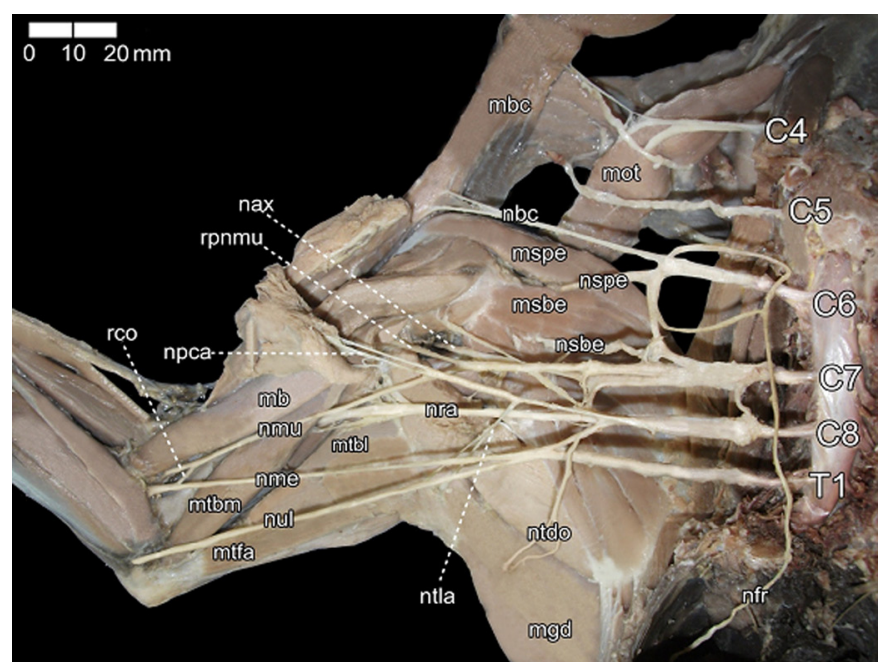

Fig.3. Origem e ramificação do plexo braquial de Cerdocyon thous adulto, fêmea, em vista ventral. C4, C5, C6, C7, C8, segmentos cervicais 4, 5, 6, 7 e 8; T1, segmento torácico 1; mb, músculo bíceps braquial; mbc, músculo braquiocefálico; mot, músculo omotransverso; mgd, músculo grande dorsal; msbe, músculo subescapular; mspe, músculo supra-espinhoso; mtbl, cabeça longa do músculo tríceps braquial; mtbm, cabeça medial do músculo tríceps braquial; mtfa, músculo tensor da fáscia do antebraço; nbc, nervo braquiocefálico; nax, nervo axilar; npca, nervo peitoral caudal; nme, nervo mediano; nra, nervo radial; nsbe, nervo subescapular; nspe, nervo supra-escapular; ntdo, nervo tóracodorsal; nul, nervo ulnar; ntla, nervo torácico lateral; nmu, nervo musculocutâneo; rco, ramo comunicante entre nervo musculocutâneo e nervo mediano; rpnmu, ramo muscular proximal do nervo musculocutâneo; nfr, nervo frênico.

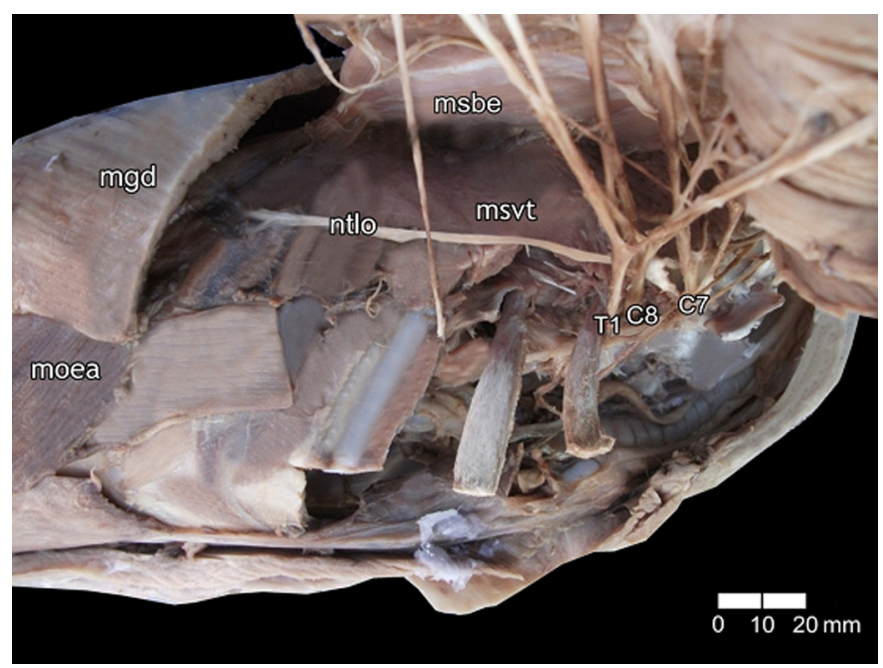

Fig.4. Vista ventrolateral do plexo braquial direito de Cerdocyon thous, fêmea, adulta, evidenciando o nervo torácico longo. C7 e C8, segmentos cervicais 7 e 8; T1, segmento torácico 1; mgd, músculo grande dorsal; msbe, músculo subescapular; msvt, músculo serrátil ventral; ntlo, nervo torácico longo; moea, músculo oblíquo externo do abdome.
Nervo musculocutâneo: originou-se de C6 e C7 em 30\%, de C7 ou da combinação de C7 com C8 em 25\% e da combinação entre C6, C7 e C8 em 20\% dos casos. Formou ramos delicados para o $\mathrm{m}$. coracobraquial e originou um importante ramo muscular proximal para o m. bíceps braquial. Deste ponto, transitou pela face medial do braço, margeando caudalmente o m. bíceps braquial e ofereceu um ramo comunicante para o n. mediano em todos os plexos. Terminou sua área de inervação motora em um ramo muscular distal para o $\mathrm{m}$. braquial.

Quadro 2. Origem e frequência dos nervos do plexo braquial que suprem os músculos intrínsecos do membro torácico de Cerdocyon thous $(\mathrm{n}=20)$

\begin{tabular}{lccc}
\hline Nervo & Ramos & Frequência & $\%$ \\
\hline Supra-escapular & C6 & 5 & 25 \\
Subescapular & C6 e C7 & 15 & 75 \\
& C6 & 2 & 10 \\
& C7 & 8 & 40 \\
Musculocutâneo & C6 e C7 & 9 & 45 \\
& C7 e C8 & 1 & 5 \\
& C7 & 5 & 25 \\
\multirow{4}{*}{ Axilar } & C6 e C7 & 6 & 30 \\
& C7 e C8 & 5 & 25 \\
& C6, C7 e C8 & 4 & 20 \\
Radial & C7 & 5 & 25 \\
& C6 e C7 & 4 & 20 \\
& C7 e C8 & 8 & 40 \\
& C6, C7 e C8 & 3 & 15 \\
Mediano & C7 e C8 & 1 & 5 \\
\multirow{4}{*}{ Ulnar } & C8 e T1 & 4 & 5 \\
& C6, C7 e C8 & 1 & 70 \\
& C7, C8 e T1 & 14 & 70 \\
& C8 e T1 & 14 & 30 \\
& C7, C8 e T1 & 6 & 80 \\
& C8 e T1 & 16 & 20
\end{tabular}

Quadro 3. Origem e frequência dos nervos do plexo braquial que suprem os músculos extrínsecos do membro torácico de Cerdocyon thous $(\mathrm{n}=\mathbf{2 0})$

\begin{tabular}{lccc}
\hline Nervo & Ramos & Freqüência & $\%$ \\
\hline Braquiocefálico & C6 & 20 & 100 \\
Torácico longo & C7 & 20 & 100 \\
Tóracodorsal & C8 & 1 & 5 \\
& C6 e C7 & 1 & 5 \\
& C7 e C8 & 1 & 5 \\
& C8 e T1 & 10 & 50 \\
Torácico lateral & C7, C8 e T1 & 7 & 35 \\
& C8 & 2 & 10 \\
& T1 & 2 & 10 \\
& C6 e C7 & 1 & 5 \\
& C7 e C8 & 2 & 10 \\
Peitoral cranial & C8 e T1 & 8 & 40 \\
& C7, C8 e T1 & 5 & 25 \\
& C7 & 5 & 25 \\
& C8 & 2 & 10 \\
& C6 e C7 & 5 & 25 \\
& C7 e C8 & 3 & 15 \\
& C8 e T1 & 1 & 5 \\
C6, C7 e C8 & 3 & 15 \\
& C7, C8 e T1 & 1 & 5 \\
& C8 & 2 & 10 \\
& T1 & 2 & 10 \\
& C6 e C7 & 1 & 5 \\
& C7 e C8 & 2 & 10 \\
& C8 e T1 & 9 & 45 \\
& C7, C8 e T1 & 4 & 20
\end{tabular}


Nervo radial: foi predominantemente formado pela combinação de C7, C8 e T1 em 70\% dos plexos, entre C8 e T1 em 20\% e entre C7 e C8 ou C6, C7 e C8 em apenas 5\%. Acompanhou o tronco comum dos nervos mediano e ulnar até o terço médio da face medial do braço, onde emitiu ramos para o m. tensor da fáscia do antebraço e atravessou o espaço entre as cabeças longa e medial do $\mathrm{m}$. tríceps braquial suprindo-as. Em seguida, contornou caudalmente a diáfise umeral e surgiu na face lateral do membro após ter inervado o m. ancôneo e as cabeças acessória e lateral do m. tríceps braquial. Neste ponto bifurcou-se em dois ramos: um profundo para os músculos craniolaterais do antebraço e outro superficial (cutâneo) que pode ser acompanhado apenas até a sua passagem sobre a face lateral da região distal do $\mathrm{m}$. braquial.

Nervo mediano: formou-se a partir de C8 e T1 em 70\% e por C7, C8 e T1 em 30\% dos casos. Surgiu em um tronco comum com o n. ulnar, tendo transitado cranialmente a este. Recebe o ramo comunicante do n. musculocutâneo em todos os plexos e foi dissecado até o ponto onde se aprofundou lateralmente sob o m. pronador redondo, inervando-o, e prosseguiu profundamente para suprir os músculos flexor radial do carpo, flexor profundo dos dedos e flexor superficial dos dedos e pronador quadrado.

Nervo ulnar: derivou suas fibras de C8 e T1 em 80\% e da combinação entre C7, C8 e T1 em 20\% dos plexos. Após separar-se do tronco comum com n. mediano, transitou sobre o epicôndilo medial do úmero e penetrou sob a cabeça ulnar do m. flexor ulnar do carpo de onde emitiu ramos para inervar porções do m. flexor profundo dos dedos e cabeça umeral do m. flexor ulnar do carpo.

Nervo braquiocefálico: foi formado invariavelmente por $\mathrm{C6}$ e se direcionou para o $\mathrm{m}$. clidobraquial do $\mathrm{m}$. braquiocefálico, imediatamente distal à clavícula rudimentar e cranialmente à articulação gleno-umeral.

Nervo torácico longo: originou-se invariavelmente a partir de C7 nos vinte membros torácicos. Percorreu um trajeto horizontal sobre a face lateral da porção torácica do m. serrátil ventral (fig 3).

Nervo tóracodorsal: teve suas fibras derivadas de C8 e T1 em 50\% dos casos e de C8 e T1 em 35\%. Derivações apenas de C8 e da combinação entre C6 e C7 ou de C7 e C8 ocorreram em somente $5 \%$ dos plexos. Acompanhou os vasos tóracodorsais satélites até suprir a face profunda $\mathrm{m}$. grande dorsal.

Nervo torácico lateral: foi resultado da combinação entre C8 e T1 em 40\% dos casos e de C7, C8 e T1 em 25\%. Outras origens menos frequentes surgiram apenas de C8, apenas de T1 ou da combinação entre C7 e C8 em 10\% dos casos. Em um único plexo foi originado de C6 e C7 (5\%). Seguiu o trajeto dos vasos torácicos laterais, transitou no espaço entre os músculos grande dorsal e peitoral profundo, suprindo o último e o m. cutâneo do tronco.

Nervo peitoral cranial: originou-se de C7 ou de C6 e C7 em 25\% dos casos, de C7 e C8 em 15\%, de C6, C7 e T1 em 15\%, de C8 em 10\%, de C8 e T1 em 5\% e de C7, C8 e T1 em $5 \%$. Direcionou-se para o m. peitoral superficial. Foi o que teve a maior variação no número de ramificações e no padrão de formação: sete formas diferentes.
Nervo peitoral caudal: teve a formação mais frequente por $\mathrm{C} 8$ e T1 em 45\% dos casos, por C7, C8 e T1 em 20\%, por C8 em 10\%, por T1 em 10\%, por C7 e C8 em 10\% e por C6 e $\mathrm{C} 7$ em 5\% dos casos. Emitiu ramos para o m. peitoral profundo.

\section{DISCUSSÃO}

\section{Quanto à origem do plexo braquial}

0 plexo braquial de Cerdocyon thous originou-se nos ramos ventrais espinhais de C6, C7, C8 e T1 em todos os cadáveres analisados. Allam et al. (1952) determinaram que esta também foi a formação mais frequente do plexo braquial em cães domésticos correspondendo a 58,62\% de 58 plexos dissecados, ainda que a contribuição de C5 e/ ou T2 tenham sido comumente observadas. Esta formação do plexo braquial também foi verificada em Connochaetes sp., Camelus sp., Coendou prehensilis (Paterson, 1887), felinos domésticos (Ghoshal 1986b, Aubert et al. 2004), ovinos, caprinos (Goshal 1986a), Capricornis crispus (Atoji et al. 1987), Myocastor coypus (Guimarães et al. 2007), Chinchilla lanigera (Gamba et al. 2007), Arctocephalus australis (Souza et al. 2010), em Mazama gouazoubira (Melo et al. 2007, Prestes et al. 2013, Vieira et al. 2013) e em Atelocynus microtis (Pinheiro et al. 2013). Mesmo sem especificar a espécie, Swan (1864) apud Paterson (1887) refere que em "raposas" apenas quatro ramos ventrais formaram o plexo braquial sem especificar quais seriam, mas supomos serem os mesmos encontrados em C. thous, visto que em todos os mamíferos levantados C6, C7, C8 e T1 formam o plexo. Allam et al. (1952) discute que esta configuração de formação do plexo braquial, praticamente confinada a quatro ramos ventrais espinhais, estaria associada à uma certa limitação de movimentos acompanhada pela ausência de clavícula e por mudanças adaptativas concomitantes nos músculos da região do ombro. No entanto, quando se confrontam as composições dos plexos descritos mais recentemente com os respectivos hábitos locomotores das espécies, verifica-se que isto não é um corolário absoluto.

Apesar de o ramo ventral de $\mathrm{C} 7$ ter predominado como a origem da maioria dos nervos no total de plexos analisados (61,5\%), sua contribuição foi maior para nervos que suprem músculos extrínsecos cuja importância motora para o membro torácico é menor. Desta forma, pode-se presumir que uma lesão ao nível de C8, que originou a maioria dos nervos para músculos intrínsecos, teria uma repercussão funcional motora mais importante. A combinação entre C8 e T1 foi a que mais formou nervos em todo o plexo $(23,8 \%)$, especialmente para músculos intrínsecos.

$O$ ponto mais cranial de origem do plexo braquial em $C$. thous foi o ramo espinhal ventral de $\mathrm{C} 6$ em todos os indivíduos dissecados. Parada et al. (1989) propõe que, durante o processo evolutivo, a origem deste plexo ascendeu no sentido cranial, alcançando o quarto nervo espinhal cervical em alguns macacos (Ribeiro et al. 2005) e terceiro espinhal cervical em humanos. No entanto, a presença de C4 na formação do plexo braquial de monotremados (Koizumi \& Sakai 1997), bicho preguiça (Amorim Júnior et al. 2003), capivaras (Fioretto et al. 2003) e catetos (Moura et al. 2007), 
mostra que a origem em ramos mais craniais não é característica apenas de espécies mais recentes. Os resultados desse trabalho corroboraram para contradizer Parada et al. (1989) pois o gênero Cerdocyon surgiu mais recentemente na escala evolutiva do que muitas destas espécies citadas, inclusive que o gênero Canis, mas apresenta a origem do plexo em um ponto mais caudal. Estes resultados dão mais coerência a Carpenter (1978) \& Moura et al. (2007) que sugerem que as mudanças na origem do plexo se devem a variações na posição de inserção dos brotos dos membros em relação ao neuro-eixo. Observa-se que o plexo braquial do C. thous tem origem idêntica e ramificação semelhante ao dos demais carnívoros, especialmente ao do cão doméstico e de Atelocynus microtis (Pinheiro et al. 2013). Portanto, parece razoável supor que as semelhanças na morfologia do plexo braquial possam ser reflexos de uma proximidade filogenética entre as espécies. Um número maior de análises da anatomia dos plexos braquiais em outras espécies carnívoras ajudaria a embasar essa suposição.

Do total de 260 nervos que tiveram sua origem estudada, 68,8\% foram originados pela combinação de dois ou três ramos espinhais ventrais, enquanto apenas 31,2\% tiveram sua formação determinada por um único ramo. Se for considerado o total de 140 nervos dissecados que supriam os músculos intrínsecos, 81,1\% formaram-se a partir de mais de uma origem, o que sugere maiores complexidade e importância funcional para estes nervos.

Ainda que todos os plexos de $C$. thous tenham derivado de C6, C7, C8 e T1, a formação de cada nervo teve variação inclusive entre antímeros de um mesmo animal, assim como verificado também na capivara por Fioretto et al. (2003). Segundo Johnson et al. (2010), variações na arquitetura neural do plexo braquial são mais regra do que exceção. Em um estudo com 200 plexos de fetos humanos abortados os autores relataram que apenas 46,5\% detinham uma organização considerada típica, enquanto $53,5 \%$ demonstraram uma variação significativa em relação ao padrão mais esperado (Uysal et al. 2003).

Melo et al. (2007) relataram que no veado catingueiro a origem do plexo braquial dos machos era mais cranial e a distribuição mais complexa do que nas fêmeas. A amostragem de $C$. thous utilizada neste estudo foi predominantemente de fêmeas (80\%), como reflexo do maior número de atropelamentos de indivíduos do sexo feminino desta espécie na região geográfica do estudo. Ainda que as amostras tenham sido desiguais, observamos um maior número de ramos ventrais e uma maior complexidade na formação do plexo das fêmeas em comparação com os dois machos analisados. Nas fêmeas, em média 1,94 ramos ventrais formavam um nervo enquanto nos machos essa média foi de 1,67 , ainda que o teste $t$ de comparação entre as médias ao nível de 5\% não tenha demonstrado diferença significativa. Uma amostragem mais equilibrada quanto ao gênero poderá esclarecer essa variação.

\section{Quanto à distribuição dos nervos do plexo braquial}

Nervos para a musculatura intrínseca. Com origem predominante em C6 e C7 (70\%) no C. thous, o nervo supra-escapular foi formado de modo semelhante no cão domés- tico (Allam et al. 1952, Ghoshal 1986b), nos equinos, nos ruminantes domésticos (Magilton et al. 1968), em Arctocephalus australis (Souza et al. 2010) e em Atelocynus microtis (Pinheiro et al. 2013). Originou-se de C5 e C6 em Papio ursinus (Booth et al. 1997), em Lagothrix lagothricha (Cruz \& Adami 2010), em Pan paniscus (Kikushi et al. 2011), em Sciurus vulgaris (Aydin 2011), em Tamandua tetradactyla (Cruz et al. 2012) e em Hippopotamus amphibius (Yoshitomi et al. 2012), de C5, C6 e C7 nos suínos (Magilton et al. 1968) e em Agouti paca (Scavone et al. 2008), de C4, C5, C6 e C7 em Hydrochaeris hydrochaeris (Fioretto et al. 2003) e em Tayassu tajacu (Moura et al. 2007), de C6, C7 e C8 em fetos de bovinos azebuados (Santos et al. 2011) e apenas de C6 nos felinos domésticos (Ghoshal 1986b), alguns caprinos (Ghoshal 1986a) e em Chinchilla lanigera (Gamba et al. 2007). Estudos eletrofisiológicos em seis cães domésticos revelaram que o n. supra-escapular recebeu potenciais evocados dos ramos ventrais de C6 e C7 em todos os animais avaliados (Sharp et al. 1991), o que reforça a importância funcional destes ramos para o nervo em canídeos. Fioretto et al. (2003) sugere que a ampla origem do n. supra-escapular em algumas espécies seria decorrente da necessidade de movimentação intensa e coordenada da musculatura escapular durante o nado. Pode-se, portanto, assumir que esta musculatura para o nado seja menos funcional em canídeos o que resultaria na origem deste nervo em apenas um ou dois ramos ventrais conforme verificado no C.thous, no A. microtis e no cão doméstico. Na contramão desta hipótese, $A$. australis é um carnívoro com membros torácicos adaptados ao nado, mas que teve o n. supra-escapular formado pelos mesmos dois ramos que predominaram em $C$. thous e no cão doméstico. Com relação ao trajeto e suprimento aos músculos supra-espinhoso e infra-espinhoso, o n. supra-escapular exibiu em $C$. thous disposição semelhante à observada no cão doméstico (Allam et al. 1952, Ghoshal 1986b, Evans \& De Lahunta 2013), nos ruminantes domésticos (Ghoshal 1986a), em P. ursinus (Booth et al. 1997), em A. paca (Scavone et al. 2008) e em fetos de bovinos azebuados (Santos et al. 2011). Diferente do que ocorreu nestas espécies o m. subescapular também foi suprido pelo n. supra-escapular em felinos domésticos (Ghoshal 1986b), em $H$. hydrochaeris (Fioretto et al. 2003)e em $M$. gouazoubira (Vieira et al. 2013). Em A. australis (Souza et al. 2010) se restringiu à inervação dos músculos subescapular e supra-espinhoso enquanto em C. lanigera (Gamba et al. 2007) e em L. lagotrichia (Cruz \& Adami 2010) inervou os músculos supra-espinhoso, infra-espinhoso e deltoide e em T. tetradactyla (Cruz et al. 2012) supriu apenas o m. supra-espinhoso.

O nervo subescapular de $C$. thous teve quatro formas distintas de origem, sendo a mais comum a proveniente de C6 e C7 (45\%) o que está condizente com as dissecções de Allam et al. (1952), com o relato de Ghoshal (1986b) e com os estudos eletrofisiológicos de Sharp et al. (1991) no cão doméstico. Estas origens também foram verificadas como predominantes nos felinos domésticos (Ghoshal 1986b), nos equinos, suínos e ruminantes domésticos (Magilton et al. 1968), em C. lanigera (Gamba et al. 2007) e em $M$. gouazoubira (Vieira et al. 2013). Origens menos frequen- 
tes deste nervo em $C$. thous foram observadas como predominantes em A. paca (Scavone et al. 2008) e A. microtis (Pinheiro et al., 2013) em que surgiu apenas de C6, e nos equinos (Magilton et al. 1968) e em A. australis (Souza et al. 2010) apenas de C7. Esta última forma também pode ocorrer em alguns casos nos pequenos ruminantes (Magilton et al. 1968). Em P. ursinus (Booth et al. 1997), em S. vulgaris (Aydin 2011), em T. tetradactyla (Cruz et al. 2012) e em H. amphibius (Yoshitomi et al. 2012) originou-se de C5 e C6, enquanto em T. tajacu (Moura et al. 2007) e em L. lagothricha (Cruz \& Adami 2010) surge de C5, C6 e C7. No entanto, em um plexo de $C$. thous foi observada a formação do $\mathrm{n}$. subescapular pela combinação de C7 e C8 (5\%), o que não aparece descrito para nenhuma outra espécie. 0 seu trajeto como nervo único na face medial do $\mathrm{m}$. subescapular com ramificação distal para suprir este músculo foi semelhante ao descrito por Allam et al. (1952) e por Evans \& De Lahunta (2013) no cão doméstico, por Booth et al. (1997) em $P$. ursinus, por Scavone et al. (2010) em A. paca e por Cruz et al. (2012) em T. tetradactyla. Os suprimentos deste nervo para o m. redondo maior, descrita como frequente no cão e gato domésticos (Ghoshal 1986b), em C. lanigera (Gamba et al. 2007), em A. australis (Souza et al. 2010), em L. lagotrichia (Cruz \& Adami 2010) e em M. gouazoubira (Vieira et al. 2013), e para o m. grande dorsal descrita nos felinos (Ghoshal 1986b) não foram encontradas em C. thous.

Mesmo que C7 tenha sido identificado como origem do nervo axilar em todos os plexos dissecados em C. thous, quatro diferentes padrões de formação para este nervo foram observados, sendo a combinação entre C7 e C8 a predominante (40\%), conforme também evidenciado no cão doméstico (Ghoshal 1986b, Evans \& De Lahunta 2013), nos equinos e bovinos (Magilton et al. 1968) e em A. australis (Souza et al. 2010). A segunda forma de origem mais frequente do n. axilar em C. thous ocorreu em $25 \%$ e era restrita a C7, assim como também encontrada no cão por Allam et al. (1952). Nos ovinos e caprinos (Magilton et al. 1968), em C. lanigera (Gamba et al. 2007), em T. tajacu (Moura et al. 2007), em A. paca (Scavone et al. 2008), em M. gouazoubira (Vieira et al. 2013) e em A. microtis (Pinheiro et al. 2013), o n. axilar se originou em C6 e C7. Em H. hydrochaeris (Fioretto et al. 2003), sua origem aconteceu em C5, C6, C7 e C8, nos suínos (Magilton et al. 1968), em P. ursinus (Booth et al. 1997), em L. lagotrichia (Cruz \& Adami 2010) e em T. tetradactyla (Cruz et al. 2012) em C5, C6 e C7, nos monotremados Ornithorhynchus anatinus e Tachyglossus aculeatus (Koizumi \& Sakai 1997) em C4, C5 e C6 e em Sciurus vulgaris (Aydin 2011) em C5 e C6. A área de inervação motora do n. axilar em $C$. thous incluiu os músculos flexores da articulação escápulo-umeral: subescapular, redondo maior, redondo menor e deltoide. Assim, verificou-se semelhança no suprimento nervoso aos músculos e no trajeto descrito para o cão doméstico por Ghoshal (1986b) e Evans \& De Lahunta (2013). A distribuição para os músculos foi semelhante também com os ruminantes domésticos (Ghoshal 1986a) e A. paca (Scavone et al. 2008). Variações nos ramos musculares deste nervo são amplas entre espécies. Por exemplo, em P. ursinus (Booth et al. 1997) supre os músculos subescapular, redondo maior, redondo menor e deltoide, em H. hydrochaeris (Fioretto et al. 2003) supre apenas a cabeça medial do tríceps braquial, em $C$. lanige$r a$ (Gamba et al. 2007) os músculos subescapular, redondo maior, deltoide e cleidobraquial, em A. australis (Souza et al. 2010) os músculos subescapular, redondo maior e deltoide, em L. lagotrichia (Cruz \& Adami 2010) os músculos redondo maior, redondo menor e deltoide e em T. tetradactyla (Cruz et al. 2012) os músculos redondo maior, redondo menor, infra-espinhoso e deltóide. 0 restante de suas delgadas ramificações em $C$. thous era cutânea.

Apesar de irregular em sua formação, o nervo musculocutâneo de $C$. thous sempre teve origem no ramo de C7, ainda que comumente com contribuições de C6 e C8, o que coincide com o descrito para o cão doméstico por Ghoshal (1986b) e por Evans \& De Lahunta (2013). A origem que mais se repetiu para este nervo em $C$. thous foi a combinação de C6 e C7 (30\%), assim como em suínos, ovinos e caprinos (Magilton et al. 1968) e em A. microtis (Pinheiro et al. 2013), ainda que outros padrões tivessem frequência muito próxima. Os estudos eletrofisiológicos de Sharp et. al (1990) no cão doméstico confirmam a importância de C7 para o n. musculocutâneo ao concluir que a maior parte do potencial evocado para o nervo era proveniente desta ramo. Allam et al. (1952) descreveram que o n. musculocutâneo originava-se apenas de C7 no cão. A origem em C6, C7 e C8 ocorreu em 20\% dos plexos de $C$. thous, sendo esta formação descrita em bovinos (Magilton et al. 1968), em $A$. paca (Scavone et al. 2008) e em M. gouazoubira (Vieira et al. 2013). Enquanto em P. ursinus (Booth et al. 1997), em $L$. lagothricha (Cruz \& Adami 2010) e em T. tetradactyla (Cruz et al. 2012) o n. musculocutâneo tem a origem mais cranial em C5 e C6 (e eventualmente C7), em várias outras espécies como em T. tajacu (Moura et al. 2007), em C. lanigera (Gamba et al. 2007) e em A. australis (Souza et al. 2010) a origem se faz mais caudal, recebendo inclusive a contribuição de T1. Nos equinos (Magilton et al. 1968) e felinos (Ghoshal 1986b) origina-se de C7 e C8. Em C. thous seu território de inervação incluiu os músculos coracobraquial, bíceps braquial e braquial em uma disposição semelhante à do cão doméstico (Evans \& De Lahunta 2013), de L. lagotrichia (Cruz \& Adami 2010) e de T. tetradactyla (Cruz et al. 2012). 0 ramo muscular proximal em $C$. thous supriu o m. bíceps braquial, assim como no cão doméstico (Allam et al. 1952, Ghoshal 1986b), em C. lanigera (Gamba et al. 2007) e em A. australis (Souza et al. 2010). Nos ruminantes domésticos (Ghoshal 1986a), nos felinos domésticos (Ghoshal 1986b), em P. ursinus (Booth et al. 1997), em A. paca (Scavone et al. 2008) e em M. gouazoubira (Vieira et al. 2013) o ramo proximal supre também o $\mathrm{m}$. coracobraquial. 0 ramo comunicante entre os nervos musculocutâneo e mediano esteve presente em todos os plexos de $C$. thous, assim como observado no cão doméstico (Allam et al. 1952), em P. ursinus (Booth et al. 1997) a um nível mais proximal, em L. lagothricha (Cruz \& Adami 2010) e em M. gouazoubira (Vieira et al. 2013). Isto é funcionalmente importante, pois permite uma continuidade da condução do estímulo mesmo após lesão proximal de um destes nervos, conforme confirmado pelos estudos eletrofisiológicos de Sharp et al. (1990) no cão doméstico. 0 ramo distal em C. thous inervou 
apenas o m. braquial, assim como acontece no cão (Allam et al. 1952), nos ruminantes domésticos (Ghoshal 1986a), em A. paca (Scavone et al. 2008) e em M. gouazoubira (Vieira et al. 2013). Em C. lanigera (Gamba et al. 2007) e A. australis (Souza et al. 2010) inervou também o m. bíceps braquial. H. amphibius (Yoshitomi et al. 2012) foi a única espécie levantada cujo n. musculocutâneo não supre o m. bíceps braquial, mas apenas os músculos coracobraquial e braquial.

0 nervo radial, maior entre todos do plexo, foi formado predominantemente pelos ramos espinhais ventrais de C7, C8 e T1 (70\%) em C. thous, assim como verificado em cães domésticos (Allam et al. 1952, Ghoshal 1986b, Evans \& De Lahunta 2013), nos suínos e ruminantes domésticos (Magilton et al. 1968), nos monotremados O. anatinus e $T$. aculeatus (Koizumi \& Sakai 1997), em C. lanigera (Gamba et al. 2007), em A. paca (Scavone et al. 2008), em A. australis (Souza et al. 2010) e em H. amphibius (Yoshitomi et al. 2012). Em felinos domésticos também se originou de C7, C8 e T1, ainda que um percentual pequeno (18\%) também recebesse contribuições de C6 (Guimarães et al. 2007), o que ocorreu em apenas $5 \%$ dos plexos de $C$. thous. 0 ramo de C8 esteve presente na formação dos vinte nervos radiais dissecados em $C$. thous. Isto é coerente tanto com as observações de Sharp et al. (1991) em cães domésticos, onde C8 deu a maior contribuição em testes com potencial evocado para este nervo, como também com o levantamento realizado sobre a formação deste nervo nas demais espécies domésticas e silvestres. Em P. paniscus (Kikushi et al. 2011) o n. radial originou-se apenas de C8, em $S$. vulgaris (Aydin 2011), M. gouazoubira (Vieira et al. 2013) e em A. microtis (Pinheiro et al., 2013) de C7 e C8, no equino de C8 e T1 (Magilton et al. 1968), em T. tajacu (Moura et al. 2007) de C8, T1 e T2, em H. hydrochaeris (Fioretto et al. 2003) de C6, C7, C8 e T1, em P. ursinus (Booth et al. 1997), em L. lagotrichia (Cruz \& Adami 2010) e em T. tetradactyla (Cruz et al. 2012) de C5, C6, C7, C8 e T1. 0 fato de a formação do n. radial ter ocorrido por três diferentes raízes em 75\% dos plexos de $C$. thous está relacionado à sua importância motora, uma vez que seus ramos inervam todos os músculos extensores das articulações do cotovelo, carpo e dedos, além do m. supinador e abdutor longo do primeiro dedo. Assim, da mesma forma que relatado para o cão (Ghoshal 1986b, Evans \& De Lahunta 1993), para C. lanigera (Gamba et al. 2007) e para A. australis (Souza et al. 2010), a área de inervação de suas ramificações incluiu os músculos tríceps braquial (todas as cabeças), tensor da fáscia do antebraço, ancôneo, extensor radial do carpo, extensor comum dos dedos, extensor lateral dos dedos, ulnar lateral, abdutor longo do primeiro dedo e supinador. Foi responsável pela inervação dos mesmos músculos, a exceção do supinador em ruminantes domésticos (Ghoshal 1986a), em A. paca (Scavone et al. 2008) e no M. gouazoubira (Vieira et al. 2013). No gato doméstico (Guimarães et al. 2007) os autores relataram inervação somente dos músculos tensor da fáscia do antebraço, tríceps braquial e ancôneo, enquanto em $H$. hydrochaeris (Fioretto et al. 2003) dos músculos tríceps braquial, ancôneo, extensor radial do carpo e extensores dos dedos.

Com origem predominante em C8 e T1 (70\%) e recebendo a contribuição de C7 nos demais casos (30\%), o ner- vo mediano de $C$. thous tem origem e distribuição idêntica à descrita para o cão doméstico por Ghoshal (1986b) e Evans \& De Lahunta (2013), embora Allam et al. (1952) não faça menção à contribuição de C7, mas sim de T2, em alguns dos 58 plexos dissecados em cães. Sharp et al. (1990) revelaram que, de fato, a maior parte do potencial evocado para o n. mediano em cães era proveniente de C8 e T1. Comparativamente, as espécies cuja origem do n. mediano se deu em C8 e T1 foram os ovinos e caprinos (Magilton et al. 1968) e A. australis (Souza et al. 2010). A contribuição de C7, C8 e T1 surgiu nos suínos (Magilton et al. 1968), nos felinos domésticos (Ghoshal 1986b), nos monotremados O. anatinus e T.aculeatus (Koizumi \& Sakai 1997), em C. lanigera (Gamba et al. 2007), em A. paca (Scavone et al. 2008), em H. amphibius (Yoshitomi et al. 2012), em M. gouazoubira (Vieira et al. 2013) e em A. microtis (Pinheiro et al. 2013). Os ramos C7 e C8 formaram o n. mediano em $S$. vulgaris (Aydin 2011), C7, C8, T1 e T2 em T. tajacu (Moura et al. 2007), C6, C7, C8 e T1 em H. hydrochaeris (Fioretto et al. 2003), C5, C6, C7, C8 e T1 em L. lagotrichia (Cruz \& Adami 2010) e em T. tetradactyla (Cruz et al. 2012) e C8, T1 e T2 nos equinos e bovinos (Magilton et al. 1968). Em C. thous o n. mediano se distribuiu para os músculos pronador quadrado, pronador redondo, flexor radial do carpo, flexor profundo dos dedos e flexor superficial dos dedos, em conformidade com o descrito para o cão doméstico por Allam et al. (1952), em C. lanigera (Gamba et al. 2007) e em M. gouazoubira (Vieira et al. 2013). Em A. australis (Souza et al. 2010) o n. mediano foi responsável pela inervação dos músculos pronador redondo, flexores superficial e profundo dos dedos e ainda o flexor radial do carpo. Nos ruminantes domésticos (Ghoshal 1986a), supriu também o m. flexor ulnar do carpo, além dos listados anteriormente. Em L. lagotrichia (Cruz \& Adami 2010) a inervação foi completamente diferente das demais espécies, suprindo os músculos braquial, bíceps braquial e a cabeça medial do tríceps braquial. Em H. amphibius (Yoshitomi et al. 2012) supriu apenas o m. braquial.

0 nervo ulnar, assim como o mediano, teve origem predominantemente em C8 e T1 (80\%), embora tenha recebido contribuições de C7 em 20\% dos casos. Isto diverge um pouco do encontrado no cão doméstico por Allam et al. (1952) e por Ghoshal (1986b) que não descrevem contribuições de C7. O primeiro menciona que os nervos mediano e ulnar de 29 cães tiveram a origem restrita a C8 e T1, com contribuições eventuais de T2. Sharp et al (1990) também observou que C8 e T1 participaram da formação do n. ulnar em todos os seis cães que analisaram, porém a contribuição de C7 ocorreu em apenas um indivíduo e originou menos de $1 \%$ das fibras eferentes para o n. ulnar e se direcionavam para o m. flexor ulnar do carpo. Em C. thous, os nervos mediano e ulnar seguiram juntamente, unidos por um frágil tecido conjuntivo, até o terço médio da face medial do braço, a partir de onde o n. ulnar seguiu um trajeto mais caudal em direção ao epicôndilo medial do úmero para inervar porções dos músculos flexor profundo dos dedos e flexor ulnar do carpo. 0 trajeto e a área de distribuição do nervo são idênticas às descritas por Allam et al (1952) e Evans \& De Lahunta (2013) para o cão doméstico. Esta 
origem do n. ulnar majoritariamente em C8 e T1 também foi relatada nos suínos, ovinos e caprinos (Magilton et al. 1968), felinos domésticos (Ghoshal 1986b), L. lagotrichia (Cruz \& Adami 2010), M. gouazoubira (Vieira et al. 2013) e A. microtis (Pinheiro et al., 2013). Nos bovinos (Magilton et al. 1968), em P. ursinus (Booth et al. 1997), em A. paca (Scavone et al. 2008) e em A. australis (Souza et al. 2010) a origem se deu em C8, T1 e T2, em Sciurus vulgaris (Aydin 2011) em C7 e C8, em T. tajacu (Moura et al. 2007) em C6, C7, C8 e T1 e em H.hydrochaeris (Fioretto et al. 2003), nos monotremados $O$. anatinus e T. aculeatus (Koizumi \& Sakai 1997), em C. lanigera (Gamba et al. 2007) e em H. amphibius (Yoshitomi et al. 2012) em C7, C8 e T1. Em T. tetradactyla (Cruz et al. 2012) surgiu amplamente de C5, C6, C7, C8 e T1. Os músculos flexor ulnar do carpo, flexor superficial dos dedos e flexor profundo dos dedos foram inervados por este nervo nos ruminantes domésticos (Ghoshal 1986a) e em M. gouazoubira (Vieira et al. 2013). Nesses últimos, inconstantemente emitiu ramos também para o $\mathrm{m}$. extensor ulnar do carpo. Em H. hydrochaeris (Fioretto et al. 2003), realizou-se a inervação dos músculos flexor radial do carpo, flexor ulnar do carpo e flexor superficial dos dedos, em C. lanigera (Gamba et al. 2007) do flexor radial do carpo e flexor profundo dos dedos e em A. australis (Souza et al. 2010) do flexor ulnar do carpo, flexor profundo dos dedos e flexores dos dedos I e II. Em L. lagotrichia (Cruz \& Adami 2010) supriu apenas a cabeça medial do m. tríceps braquial juntamente com o n. mediano.

De modo agrupado pode-se verificar que, entre os nervos que suprem a musculatura intrínseca do membro torácico de $C$. thous, aqueles que terminam suas áreas de inervação em nível proximal à articulação úmero-rádio-ulnar (supra-escapular, subescapular, axilar e musculocutâneo) têm origem nos ramos mais craniais do plexo, ou seja, em C6, C7 e menos comumente C8. Os demais nervos (radial, mediano e ulnar), que seguem até as regiões distais do membro para suprir músculos extensores e flexores do carpo e dígitos, tiveram origem concentrada em C8 e T1. Além disso, os nervos com localização restrita proximalmente demonstraram, em alguns casos, origem em um único ramo, o que não ocorreu naqueles com trajeto mais longo distalmente.

Nervos para a musculatura extrínseca. 0 nervo braquiocefálico foi proveniente de $\mathrm{C} 6$ em todos os plexos de C. thous e exibiu trajeto e área de inervação sobre m. clidobraquial semelhantes ao descrito para o cão (Evans \& De Lahunta 2013). Embora os estudos de anatomia e eletrofisiologia citem com frequência a contribuição de C7 na formação deste nervo no cão, alguns autores são unânimes em apontar C6 como seu principal ramo formador (Allam et al. 1952, Sharp et al. 1991). Apesar de não ser listado pelo International Committee on Veterinary Gross Anatomical Nomenclature (2012), optamos por concordar com os autores que pesquisam e descrevem o plexo braquial de cães (Allam et al. 1952, Sharp et al. 1991, Evans \& De Lahunta 2013) ao reconhecer que, do ponto de vista morfofuncional, este nervo é parte do plexo braquial visto que satisfaz a duas condições: tem origem em $\mathrm{C} 6$ e seu território de inervação abrange um importante músculo extrínseco do membro torácico com fixação na área braquial. Entretanto, não encontramos citação deste nervo em outras espécies que não nos cães domésticos. Em C. thous, juntamente com o n. torácico longo, foi um dos nervos com maior constância na formação.

Com origem invariável de $\mathrm{C} 7$ nos vinte plexos dissecados de $C$. thous, o nervo torácico longo exibiu trajeto horizontal e destacado dos demais nervos sobre a porção torácica do m. serrátil ventral, suprindo-o. Essa descrição de origem, percurso e área de inervação é idêntica à do cão doméstico (Evans \& De Lahunta 2013) e de L. lagotrichia (Cruz \& Adami 2010). A origem em C7 e C8 foi relatada nos equinos, suínos e ruminantes domésticos (Magilton et al. 1968), no cão doméstico (Ghoshal 1986b), em C. lanigera (Gamba et al. 2007), em T. tajacu (Moura et al. 2007), em A. paca (Scavone et al. 2008), em A. australis (Souza et al. 2010), em $P$. paniscus (Kikushi et al. 2011) e em M. gouazoubira (Vieira et al. 2013). Em P. ursinus (Booth et al. 1997) foi formado pelos ramos de $\mathrm{C} 6$ e $\mathrm{C} 7$ e em H. hydrochaeris (Fioretto et al. 2003) de C6, C7 e C8. Tanto quanto em C. thous, este nervo também foi responsável pela inervação do $\mathrm{m}$. serrátil ventral em P. ursinus (Booth et al. 1997) e em M. gouazoubira (Vieira et al. 2013). Em A. paca (Scavone et al. 2008) o principal músculo inervado pelo $n$. torácico longo foi o grande dorsal.

Os nervos peitorais craniais em $C$. thous tiveram sete combinações de origens diferentes e nenhuma predominante. Este resultado está de acordo com o relatado por Ghoshal (1986b) e Evans \& De Lahunta (2013) para o cão doméstico onde se refere aos nervos peitorais craniais como irregulares em número e origem, mas usualmente proveniente dos ramos de C6, C7 e C8. De fato, isto também foi verificado em $90 \%$ dos plexos de $C$. thous, ainda que $10 \%$ tenham demonstrado contribuições discretas de T1. Os nervos peitorais craniais supriram o m. peitoral superficial, bem como relatado para o cão (Ghoshal 1986b). Os nervos peitorais caudais também apresentaram padrões de formação diferentes, no entanto predominou a combinação entre C8 e T1 em 40\% dos casos. 0 ramo de T1 esteve presente em $75 \%$ dos plexos, confirmando a origem mais caudal em comparação ao n. peitoral cranial. Ao estudar seis cães domésticos, Sharp et al. (1991) determinaram que C8 estava presente na formação de todos os nervos peitorais caudais, enquanto T1 contribuiu em 66\% e C7 em apenas $16 \%$. No $C$. thous, foi encontrada discreta contribuição de C6 em um dos plexos (5\%), o que ainda não foi relatado no cão. A distribuição da inervação foi restrita às diferentes áreas do m. peitoral profundo, assim como descrito no cão (Ghoshal 1986b). Usualmente os autores descrevem a origem dos nervos peitorais conjuntamente nas demais espécies, o que determina um número maior de raízes na sua formação. Estes relatos determinam que os nervos peitorais foram originados de C5, C6, C7, C8 e T1 ema A. paca (Scavone et al. 2008), C5, C6 e C7 em P. ursinus (Booth et al. 1997), C6 e C7 em L. lagothricha (Cruz \& Adami 2010), C6, C7, C8 e T1 em A. australis (Souza et al. 2010), C8 e T1 em M. gouazoubira (Vieira et al. 2013), C7 e C8 nos equinos, suínos e ruminantes domésticos (Magilton et al. 1968), nos felinos domésticos (Ghoshal 1986b), em T. tajacu (Moura 
et al. 2007), em $S$. vulgaris (Aydin 2011) e C7, C8 e T1 em $C$. lanigera (Gamba et al. 2007), em T. tetradactyla (Cruz et al. 2012) e em A. microtis (Pinheiro et al. 2013). Assim como verificado em $C$. thous, também foram responsáveis pela inervação dos músculos peitorais superficial e profundo nos ruminantes domésticos (Ghoshal 1986a), em C. lanigera (Gamba et al. 2007), em A. paca (Scavone et al. 2008), em A. australis (Souza et al. 2010) e em M. gouazoubira (Vieira et al. 2013). Em P. ursinus (Booth et al. 1997) supriu também os músculos cutâneo do tronco e subclávio.

Tendo a combinação de C8 e T1 como a origem mais frequente (50\%) em $C$. thous, o nervo tóracodorsal também recebeu contribuições de C6 e de C7 em 5 e 40\% dos plexos, respectivamente. Evans \& De Lahunta (2013) afirmaram que este nervo é formado primariamente pelo ramo de C8 com possíveis contribuições de C7 e/ou T1 nos cães. Em $C$. thous, a ramo de C8 também foi a mais importante, pois esteve presente em $95 \%$ dos nervos tóracodorsais dissecados, sendo a ramo de $\mathrm{T} 1$ a segunda mais frequente na formação deste nervo (85\%). Entretanto, na análise com potenciais evocados, Sharp et al. (1991) determinaram que C7 e C8 eram os ramos mais funcionais para este nervo no cão. Quando comparado a outras espécies, o n. tóracodorsal originou-se apenas de C6 em A. australis (souza et al. 2010), de C6, C7 e C8 em T. tajacu (Moura et al. 2007), de C6, C7, C8 e T1 em H. hydrochaeris (Fioretto et al. 2003), de C7, C8 e T1 em T. tetradactyla (Cruz et al. 2012), de C5, C6, C7, C8 e T1 em P. ursinus (Booth et al. 1997) e em $L$. lagotrichia (Cruz \& Adami 2010), de C7 e C8 nos suínos, bovinos e em alguns ovinos (Magilton et al. 1968) e em M. gouazoubira (Vieira et al. 2013), de C8, T1 e T2 em $A$. paca (Scavone et al. 2008), de C8 e T1 nos equinos, ovinos e caprinos (Magilton et al. 1968), fetos bovinos azebuados (Santos et al. 2010) e em A. microtis (Pinheiro et al., 2013), e apenas de C8 em C. lanigera (Gamba et al. 2007). Em C. thous foi responsável pela inervação exclusiva do m. grande dorsal, assim como no cão doméstico (Evans \& De Lahunta 2013), nos bovinos e caprinos (Ghoshal 1986a), em P. ursinus (Booth et al. 1997), em H. hydrochaeris (Fioretto et al. 2003), em C. lanigera (Gamba et al. 2007), em A. paca (Scavone et al. 2008), em A. australis (Souza et al. 2010) e em $L$. lagotrichia (Cruz \& Adami 2010). Em M. gouazoubira (Vieira et al. 2013) inervou também o m. redondo maior. Em ovinos (Ghoshal 1986a) e fetos bovinos azebuados (Santos et al. 2010) supriu os músculos grande dorsal, redondo maior e peitoral profundo.

O n. torácico lateral em $C$. thous teve origem predominante em C8 e T1 (40\%), ainda que outras formações com discretas contribuições de C6 e/ou C7 tenham surgido. Esta formação entre C8 e T1 também é relatada como a prin-

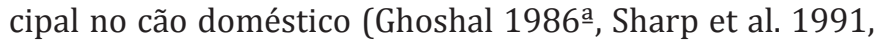
Evans \& De Lahunta 2013), nos suínos, ovinos e caprinos (Magilton et al. 1968), em C. lanigera (Gamba et al. 2007), em A. australis (Souza et al. 2010) e em M. gouazoubira (Vieira et al. 2013). Nos equinos e bovinos (Magilton et al. 1968), em T. tajacu (Moura et al. 2007) e em A. paca (Scavone et al. 2008) incluiu também a ramo ventral de T2. Desta forma, diferente do verificado em $C$. thous, em nenhuma das demais espécies comparadas houve participação de C6 na formação do n. torácico lateral e apenas em H. hydrochaeris (Fioretto et al. 2003) e em T. tetradactyla (Cruz et al. 2012) houve contribuição de $\mathrm{C} 7$ às demais raízes para este nervo. Sua área de inervação incluiu partes dos músculos peitoral profundo e cutâneo do tronco próximo à região axilar, assim como no cão doméstico (Evans \& De Lahunta 2013). Esta atribuição nervosa não se repetiu nas outras espécies pois, em M. gouazoubira (Vieira et al. 2013) supriu também os músculos grande dorsal e oblíquo abdominal externo e nos ruminantes domésticos (Ghoshal 1986a), em H. hydrochaeris (Fioretto et al. 2003), em C. lanigera (Gamba et al. 2007), em A. paca (Scavone et al. 2008), em A. australis (Souza et al. 2010) e inervou apenas o m. cutâneo do tronco.

Como se pode constatar, trabalhos comparativos com nervos do plexo braquial em animais são realizados desde o século XIX e muitas espécies ainda não têm a morfologia destes nervos documentada. As descrições em artigos científicos do plexo braquial de carnívoros silvestres restringem-se às de um cadáver de urso polar (Matsushima 1966), dois cadáveres de lobo-marinho (Souza et al. 2010) e um de A. microtis (Pinheiro et al., 2013), predominando os estudos com roedores e ruminantes. Quando considerados os estudos em plexos de mamíferos silvestres, usualmente emprega-se um número restrito de indivíduos devido à dificuldade na obtenção de cadáveres em condições ideais para dissecção. Trabalhos referentes à anatomia do C. thous são recentes e a maioria considerada por vezes preliminar pelos próprios autores, pois apresenta análises baseadas em apenas um a três indivíduos. Diante deste contexto, consideramos a amostragem de dez cadáveres utilizada nesse estudo satisfatória, ainda que não possa inferir a presença de dimorfismo sexual no plexo braquial do cachorro-do-mato, como ocorreu em M. gouazoubira (Melo et al. 2007) e de também não permitir esclarecer uma variação relativamente alta na formação dos nervos nesta espécie. Eventuais diferenças em nível subespecífico podem surgir, pois, baseado apenas na distribuição geográfica, supõe-se que os cadáveres recolhidos tenham sido da subespécie C. thous entrerianus (Berta 1982, Tchaicka et al. 2007). 0 conhecimento das particularidades morfológicas do plexo braquial do cachorro-do-mato podem fornecer embasamento anatômico futuro para o diagnóstico de disfunções neuromusculares, técnicas de bloqueio anestésico e análises comparativas filogenéticas desta espécie.

\section{CONCLUSÕES}

Os resultados deste estudo permitem concluir que embora o plexo braquial de Cerdocyon thous tenha apresentado origem nos ramos ventrais espinhais de C6, C7, C8 e T1 e território de inervação semelhante ao do cão doméstico, a formação dos nervos apresentou uma variação maior entre indivíduos.

O ramo de $\mathrm{C} 7$ foi o que mais contribuiu na formação do plexo, principalmente para inervação de músculos extrínsecos.

O ramo de $\mathrm{C} 8$ foi o que mais originou nervos para a musculatura intrínseca e a combinação entre os ramos de C8 e T1 foi a que originou o maior número de nervos.

A coleta de animais nas rodovias mostrou-se útil como 
forma de revelar características macroscópicas da anatomia dos nervos periféricos sem interferir na conservação da espécie.

\section{REFERÊNCIAS}

Allam M.W., Lee D.G., Nulsen F.E. \& Fortune E.A. 1952. The anatomy of the braquial plexus of the dog. Anat. Rec. 1(114):173-180.

Amorim Júnior A.A., Amorim M.J.A.A.L., Silva D.R., Pimentel D.S., Araújo F.P. \& Alvim M.M.S. 2003. Origem do plexo braquial no bicho-preguiça (Bradypus variegatus Shinz,1825). Int. J. Morphol. 21:357-362.

Atoji Y., Yoshitaka S. \& Sugimura M. 1987. Brachial and Lumbosacral plexuses and brain of the Japanese serow, p.257-268. In: Soma H. (Ed.), The Biology and Management of Capricornis and Related Mountain Antelopes. Springer, Netherlands. 398p.

Aubert L., Carozzo C., Devillaire A.C., Crevier-Denoix N. \& Moissonnier P. 2004. Macro and microanatomical characterization of the cat brachial plexus. Cells Tiss. Org. 176:205-210.

Aydin A. 2003. Brachial plexus of the porcupine (Hystrix cristata). Vet. Med. Czech 48(10):301-304.

Aydin A. 2011. The spinal nerves that constitute the brachial plexus in the red squirrel (Sciurus vulgaris). Veterinarni Medicina 56(8):405-408.

Aydin A. \& Karan M. 2012. The spinal nerves forming the brachial plexus in mole-rats (Spalax leucodon) Veterinarni Medicina 57(8):430-433.

Barisson J.D., Louro C.H., Dias S.J.T., Jojima F.S., Ferreira M.S. \& Oliveira F.S. 2012. Anatomo-radiographic description of the axial skeleton of the crab-eating fox (Cerdocyon thous). Pesq. Vet. Bras. 32(Supl.1):1-3.

Benedicto H.G., Senos R. \& Muniz T. 2008. Description of gluteal nerves in a crab-eating fox (Cerdocyon thous). Braz. J. Morphol. Sci. 25:18.

Benedicto H.G. \& Senos R. 2008. Distribuition of the femoral artery in a crab-eating fox (Cerdocyon thous). Braz. J. Morphol. Sci. 25:19.

Berta A. 1982. Cerdocyon thous. Mammalian Species, Washington, 186:1-4.

Booth K.K., Amorim M.J.A.A.L., Silva D.R., Pimentel D.S., Araújo F.P. \& Alvim M.M.S. 1997. The brachial plexus in the Chacma baboon (Papio ursinus). J. Med. Primat. 26:196-203.

Caldeira B.C., Rêgo de Paula T.A., Matta S.L.P., Balarini M.K. \& Campos P.K.A. 2010. Morphometry of testis and seminiferous tubules of the adult crabeating fox (Cerdocyon thous Linnaeus, 1766). Revta Ceres 57:569-575.

Carpenter M.B. 1978. Neuroanatomia Humana. 7aㅡ ed. Interamericana, Rio de Janeiro. 770p.

Carvalho N.C., Mattos K. \& Souza Junior P. 2012. Análise comparativa da anatomia do plexo braquial entre os canídeos silvestres Lycalopex gymnocercus e Cerdocyon thous e o cão doméstico. Anais IV Salão Internacional de Ensino, Pesquisa e Extensão, Bagé, RS. (Resumo)

Cheida C.C., Nakano-Oliveira E., Fusko-Costa R., Rocha-Mendes F. \& Quadros J. 2011. Ordem Carnívora, p.235-288. In: Reis N.R., Peracchi A.L., Pedro W.A. \& Lima I. (Eds), Mamíferos do Brasil. 2ª ed. Nelio R. dos Reis, Londrina.

Christiansen P. 1999. Scaling of mammalian long bones: small and large mammals compared. J. Zool. 247:333-348.

Cooper G. \& Schiller A.L. 1975. Anatomy of the Guinea Pig. Harvard University Press, Massachusetts. 392p.

Cruvinel A.C., Mota P.S., Lopes G.C., Rosa M.C.B., Zampieri M.M., Birck A.J., Filadelpho A.L. \& Guimarães G.C. 2012. Anatomia do Plexo Braquial do Tamanduá Mirim (Tamandua tetradactyla). Revta Cient. Eletr. Med. Vet. 10(19). Disponível em < http://www.revista.inf.br/veterinaria19/artigos/art07.pdf>

Cruz G.A.M. \& Adami M. 2010. Anatomia do plexo braquial de macaco-barrigudo (Lagothrix lagothricha). Pesq. Vet. Bras. 30:881-886.

Cruz G.A.M., Adami M., Almeida A.E.F.S., Silva E.A.A.C., Faria M.M.M.D., Pinto M.G.F. \& Silva R.D.G. 2012. Características anatômicas do plexo braquial de tamanduá-mirim (Tamandua tetradactyla Linnaeus, 1758) Revta Bras. Saúde Prod. Anim. 13:712-719.

Evans H.E. \& De Lahunta A. 2013. Spinal nerves, p.611-656. In: Ibid. (Eds), Miller's Anatomy of the Dog. $4^{\text {th }}$ ed. Saunders Elsevier, Philadelphia.
Ferguson S.H. \& Larivière S. 2004. Are long penis bones an adaption to high latitude snowy environments? Oikos. 105:255-267.

Finarelli J.A. \& Goswami A. 2009. The evolution of orbit orientation and encephalization in the Carnivora (Mammalia). J. Anat. 214:671-678.

Fioretto E.T., Castro M.F.S., Guidi W.L., Mainardi R., Souza R.R. \& Ribeiro A.A.C.M. 2003. Gross anatomic organization of the capybara's (Hydrochaeris hydrochaeris) brachial plexus. Anat. Hist. Embriol. 32:169-174.

Freeman P.M., Harcourt-Brown T.R., Jeffery N.D. \& Granger N.J. 2009. Electrophysiologic evidence of polyneuropathy in a cat with signs of bilateral brachial plexus neuropathy. J. Am. Vet. Med. Assoc. 234:240-244.

Futema F., Fantoni D.T., Auler-Jr J.O.C., Cortopassi S.R.G., Acaui A. \& Stopiglia A.J. 1999. Nova técnica de bloqueio do plexo braquial em cães. Ciência Rural 29:63-69.

Gamba C.B., Castro T.F., Rickes E.M. \& Pereira M.A.M. 2007. Sistematização dos territórios nervosos do plexo braquial em chinchila (Chinchilla lanigera). Braz. J. Vet. Res. Anim. Sci. 44:283-289.

Ghoshal N.G. 1986a. Sistema nervoso dos ruminantes: nervos espinhais, p.1052-1077. In: Getty R. (Ed.), Sisson/Grossman Anatomia dos Animais Domésticos. Vol.1. 5⿳亠丷厂 ed. Guanabara Koogan, Rio de Janeiro.

Ghoshal N.G. 1986b. Sistema nervoso do carnívoro: nervos espinhais, p.1595-1617. In: Getty R. (Ed.), Sisson/Grossman Anatomia dos Animais Domésticos. Vol.2. 5a ed. Guanabara Koogan, Rio de Janeiro.

Guimarães G.C., Machado M.R.F., Santos A.L.Q., Miglino M.A. \& Cattelan J.W. 2007. Origem, ramificação e distribuição do nervo radial no braço do gato doméstico (Felis catus domesticus Linnaeus, 1758). Braz. J. Vet. Res. Anim. Sci. 44:261-267.

Guimarães R.T., Birck A.J., Filadelpho A.L., Guimarães G.C. \& Barcelos R.P. 2013. Origem e distribuição do plexo braquial no nutria (Myocastor coypus). Revta Cient. Eletr. Med. Vet. 9(20). Disponível em <http://www. revista.inf.br/veterinaria20/artigos/AE201215.pdf>

Goswami A. 2006. Morphological integration in the carnivoran skull. Evolution 60:169-183.

Heleno A.R., Santos L.M., Miglino M.A., Peres J.A. \& Guerra R.R. 2011. Biometry, histology, and morphometry of the digestive system of wild crab-eating fox (Cerdocyon thous). Biotemas 24:111-119.

International Committee on Veterinary Gross Anatomical Nomenclature 2012. Nomina Anatomica Veterinaria. $5^{\text {th }}$ ed. Editorial Committee, Knoxville. $177 \mathrm{p}$.

Johnson E.O., Vekris M., Demesticha T. \& Soucacos P.N. 2010. Surg. Radiol. Anat. 32:291-297

Kikushi Y., Oishi M. \& Shimizu D. 2011. Morphology of brachial plexus and axillary artery in bonobo (Pan paniscus). Anat. Hist. Embryol. 40: 68-72.

Koizumi M. \& Sakai T. 1997. On the morphology of the brachial plexus of the platypus (Ornithorhynchus anatinus) and the echidna (Tachyglossus aculeatus). J. Anat., London, 190:447-455

König H.E., Liebich H.G. \& Cerveny C. 2011. Sistema nervoso, p.509-580. In: König H.E. \& Liebich H.G. (Eds), Anatomia dos Animais Domésticos: texto e atlas colorido. $4^{\mathrm{a}} \mathrm{ed}$. Artmed, Porto Alegre.

Langguth A. 1975. Ecology and evolution in the South American canids, p.192-206. In: Fox M.W. (Ed.), The Wild Canids: their systematics, behavioral ecology and evolution. Dogwise Publishing, Washington, DC.

Lorenzão C.J., Zimpel A.V., Novakoski E., Teichmann C.E. \& Martinez-Pereira M.A. 2012. Dados preliminares sobre a formação do plexo lombossacral em graxaim-do-mato (Cerdocyon thous) e graxaim-do-campo (Dusicyon gymnocercus). Anais XII Seminário Interinstitucional de Ensino, Pesquisa e Extensão da Unicruz. (Resumo) Disponível em <http:// www.unicruz.edu.br/seminario/downloads/anais/ccs/dados\%20preliminares $\% 20$ sobre\%20a\%20formacao\%20do\%20plexo\%20lombossacral\%20em\%20graxaim-do-mato.pdf>

Lugoch G., Tavares N.C. \& Souza Junior P. 2012. Comparação da formação anatômica entre os nervos do plexo lombossacral que suprem o membro pélvico de Cerdocyon thous (graxaim-do-mato) e Lycalopex gymnocercus (graxaim-do-campo). Anais IV Salão Internacional de Ensino, Pesquisa e Extensão, Bagé, RS. (Resumo)

Lyras G.A. \& Van der Geer A.A.E. 2003. External brain anatomy in rela- 
tion to the phylogeny of Caninae (Carnivora: Canidae). Zool. J. Linn. Soc. 138:505-522.

Machado F.A. \& Hingst-Zaher E. 2009. Investigating South American biogeographic history using patterns of skull shape variation on Cerdocyon thous (Mammalia: Canidae). Biol. J. Linn. Soc. 98:77-84.

Magilton J.H., Getty R. \& Ghoshal N.G. 1968. A comparative morphological study of the brachial plexus of domestic animals (goat, sheep, ox, pig and horse). Iowa State J. Sci. 42:245-279.

Matsushima R. 1966. The brachial plexus in the polar bear. Hiroshima Med. J. 13:4-5 (Apud Yoshitomi et al. 2012)

Mattos K., Carvalho N.C. \& Souza Junior P. 2012. Descrição anatômica e mensuração da laringe do Cerdocyon thous (Linnaeus, 1766). Anais do XXI Congresso de Iniciação Científica da UFPel, Pelotas, RS. (Resumo)

Menezes L.T., Santos A.L.Q., Moraes F.M. De, Kaminishi A.P.S., Leonardo T.G. \& Nascimento L.R. 2011. Anatomical types of renal arteries in crab-eating fox (Cerdocyon thous - Hamilton-Smith, 1839). Pubvet 5:1074.

Melo S.R., Gonçalves A.F., Castro Sasahara T.H., Fioretto E.T., Gerbasi S.H., Machado M.R., Guimarães G.C. \& Ribeiro A.A. 2007. Sex-related macrostructural organization of the deer's brachial plexus. Anat. Histol. Embryol. 36:295-299.

Moura C.E.B., Albuquerque J.F.G., Magalhães M.S., Silva N.B., Oliveira M.F. \& Papa P.C. 2007. Análise comparativa da origem do plexo braquial de catetos (Tayassu tajacu). Pesq. Vet. Bras. 27(9):357-362.

Nascimento L.R., Canella V.M., Guimarães G.C. \& Gonçalez P.O. 2010. Aspectos anatômicos e biométricos do aparelho digestório do cachorro-do-mato, Cerdocyon thous (Linnaeus, 1766). Anais VI Encontro sobre Animais Selvagens e Simpósio sobre Medicina e Conservação da Fauna do Cerrado, Uberlândia, MG. 32p.

Parada H., Pineda U.H., Lagunas E.M. \& Vidal H.A. 1989. Variaciones anatômicas de las ramas raquídeas que constituyen los troncos de origen del plexo braquial. Anal. Anat. Normal 7:32-36.

Paterson A.M. 1887. The limb plexuses of mammals. J. Anat. Physiol. 21:611-634.

Pinheiro L.L., Lima A.R., Souza A.C.B., Pereira L.C. \& Branco E.R. 2011. Topografia do cone medular do cachorro-do-mato (Cerdocyon thous Linnaeus, 1766): relato de caso. Biotemas 24:129-133.

Pinheiro L.L., Souza D.C., Branco E., Souza A.C.B., Pereira L.C. \& Lima A.R. 2013. Descrição do plexo braquial do cachorro-do-mato-de-orelhas-curtas (Atelocynus microtis Sclater, 1882): relato de caso. Biotemas 26:203-209.

Prestes F.O., Guimarães R.T., Birck A.J., Filadelpho A.L., Guimarães G.C. \& Barcelos R.P. 2013. Origem e distribuição do plexo braquial no veado catingueiro (Mazama gouazoubira). Revta Cient. Eletr. Med. Vet. 9(20). Disponível em <http://www.revista.inf.br/veterinaria20/artigos/AE201216.pdf>

Ribeiro A.R., Prada I.L.S., Barros R.A.C. \& Silva D.C.O. 2005. Origem do plexo braquial do macaco Cebus apella. Braz. J. Vet. Res. Anim. Sc. 42:143-149.

Santana J.J., Albuquerque J.F.G., Moura C.E.B., Costa W.P., Oliveira M.F., Barreto Júnior R.A. \& Miglino M.A. 2003. Origem do plexo braquial de mocós (Kerodon rupestris Wied, 1820). Braz. J. Vet. Res. Anim Sc. 40:391-396.

Santos L.A., Silva F.O.C., Eurides D., Guimarães E.C., Lizardo F.B., Sousa G.C., Facury Neto M.A., Cabral L.G. \& Santos V.M. 2010. Origem e distribuição do nervo toracodorsal em fetos de bovinos azebuados. Biosci. J. 26:948-955.

Santos L.A., Silva F.O.C., Eurides D., Guimarães E.C., Lizardo F.B., Sousa G.C., Facury Neto M.A., Srour H.A. \& Santos V.M. 2011. Origem e distribuição do nervo supra-escapular em fetos de bovinos azebuados. Biotemas 24:69-75.
Scavone A.R.F., Machado M.R.F., Guimarães G.C., Oliveira F.S. \& Gerbasi S.H.B. 2008. Análise da origem e distribuição dos nervos periféricos do plexo braquial da paca (Agouti paca Linnaeus, 1766). Ciênc. Anim. Bras. 9:1046-1055

Sharp J.W., Bailey C.S., Johnson R.D. \& Kitchell R.L. 1990. Spinal nerve root origin of the median, ulnar and musculocutaneous nerves and their muscle nerve branches to the canine forelimb. Anat. Histol. Embryol. 19:359-368.

Sharp J.W., Bailey C.S., Johnson R.D. \& Kitchell R.L. 1991. Spinal root origin of the radial nerve and nerves innervating shoulder muscles of the dog. Anat. Histol. Embryol. 20:205-214.

Souza D.A.S., Castro T.F., Franceschi R.C., Silva Filho R.P. \& Pereira M.A.M. 2010. Formação do plexo braquial e sistematização dos territórios nervosos em membros torácicos de lobos marinhos Arctocephalus australis. Braz. J. Vet. Res. Anim. Sc. 47:168-174.

Souza Junior P., Pinto R.J.F., Freitas A.B. \& Carvalho N.C. 2013. Morfometria do forame mandibular de Cerdocyon thous (Linnaeus, 1766), cachorro-do-mato. Biotemas 26:175-183.

Swan J. 1864. Illustrations of comparative anatomy of the nervous system. Kessinger Legacy Reprints. (Apud Paterson 1887)

Takemura C.M., Cesar J.R.R.M., Arantes R.A.T., Costa L.F., Hingst-Zaher E., Bonato V. \& Reis S.F. 2004. Morphometrical data analysis using wavelets. Real-Time Imag. 10:239-250.

Tchaicka L., Eizirik E., Oliveira T.G., Cândido Junior J.F. \& Freitas T.R.O. 2007. Phylogeography and population history of the crab-eating fox (Cerdocyon thous). Mol. Ecol. 16:819-838.

Uysal I.I., Seker M., Karabulut A.K., Buyukmumcu M. \& Ziylan T. 2003. Brachial plexus variations in human fetuses. Neurosurg. 53:676-684.

Vaz M.G.R., Lima A.R., Souza A.C.B., Pereira L.C. \& Branco E. 2011. Estudo morfológico dos músculos do antebraço de cachorro-do-mato-de-orelhas-curtas (Atelocynus microtis) e cachorro-do-mato (Cerdocyon thous). Biotemas 24:121-127.

Vieira L.G., Ribeiro P.R.Q., Lima M.O., Souza R.R., Valdes S.A.C. \& Santos A.L.Q. 2013. Origens e ramificações do plexo braquial do veado catingueiro Mazama gouazoubira (Artiodactyla: Cervidae). Biotemas 26: 137-146.

Wakuri S., Kano Y. \& Hori H. 1970. Anatomical study of the brachial plexus of a giraffe (Giraffa australis L.). Jyui Chikusan Shinpo 521:627-631. (Apud Yoshitomi et al. 2012)

Wakuri H. \& Y. Kano. 1966. Anatomical study of the Plexus brachialis of an Indian elephant (Elephas maximus L.). Bull. Azabu Vet. Coll. 15:1-12. (Apud Yoshitomi et al. 2012)

Yoshitomi S., Kawashima T., Murakami K., Takayanagi M., Inoue Y., Aoyagi R. \& Sato F. 2012. Anatomical architecture of the Brachial Plexus in the Common Hippopotamus (Hippopotamus amphibius) with Special Reference to the Derivation and Course of its Unique Branches. Anat. Histol. Embryol. 41:280-285.

Zimpel A.V., Lorenzão C.J., Novakoski, E., Teichmann C.E. \& Martinez-Pereira M.A. 2012. Dados preliminares sobre a formação do plexo braquial em graxaim-do-mato (Cerdocyon thous) e graxaim-do-campo (Dusicyon gymnocercus). Anais do XII Seminário Interinstitucional de Ensino Pesquisa e Extensão da Unicruz, Santa Cruz do Sul, RS. (Resumo) Disponível em http://www.unicruz.edu.br/seminario/downloads/anais/ ccs/dados $\% 20$ preliminares $\% 20$ sobre $\% 20$ a $\% 20$ formacao $\% 20$ do $\% 20$ plexo\%20braquial\%20em\%20graxaim-do-mato\%20.pdf> Acesso em 16 abr. 2013. 